\title{
Evaluation of simulated photochemical partitioning of oxidized nitrogen in the upper troposphere
}

\author{
B. H. Henderson ${ }^{1,2}$, R. W. Pinder ${ }^{2}$, J. Crooks ${ }^{2}$, R. C. Cohen ${ }^{3}$, W. T. Hutzell ${ }^{2}$, G. Sarwar ${ }^{2}$, W. S. Goliff ${ }^{4}$, \\ W. R. Stockwell ${ }^{5}$, A. Fahr ${ }^{5}$, R. Mathur ${ }^{2}$, A. G. Carlton ${ }^{6}$, and W. Vizuete ${ }^{1}$ \\ ${ }^{1}$ Department of Environmental Science and Engineering, University of North Carolina, Chapel Hill, NC, USA \\ ${ }^{2}$ National Exposure Research Laboratory, US Environmental Protection Agency (USEPA), RTP, NC, USA \\ ${ }^{3}$ Departments of Chemistry and Earth and Planetary Sciences, University of California, Berkeley, CA, USA \\ ${ }^{4}$ College of Engineering-CERT, University of California at Riverside, Riverside, CA, USA \\ ${ }^{5}$ Department of Chemistry, Howard University, Washington, DC, USA \\ ${ }^{6}$ Department of Environmental Sciences, Rutgers University, New Brunswick, NJ, USA
}

Received: 7 August 2010 - Published in Atmos. Chem. Phys. Discuss.: 25 August 2010

Revised: 13 December 2010 - Accepted: 1 January 2011 - Published: 14 January 2011

\begin{abstract}
Regional and global chemical transport models underpredict $\mathrm{NO}_{\mathrm{x}}\left(\mathrm{NO}+\mathrm{NO}_{2}\right)$ in the upper troposphere where it is a precursor to the greenhouse gas ozone. The $\mathrm{NO}_{\mathrm{x}}$ bias has been shown in model evaluations using aircraft data (Singh et al., 2007) and total column $\mathrm{NO}_{2}$ (molecules $\mathrm{cm}^{-2}$ ) from satellite observations (Napelenok et al., 2008). The causes of $\mathrm{NO}_{\mathrm{x}}$ underpredictions have yet to be fully understood due to the interconnected nature of simulated emission, transport, and chemistry processes. Recent observationbased studies, in the upper troposphere, identify chemical rate coefficients as a potential source of error (Olson et al., 2006; Ren et al., 2008). Since typical chemistry evaluation techniques are not available for upper tropospheric conditions, this study develops an evaluation platform from in situ observations, stochastic convection, and deterministic chemistry. We derive a stochastic convection model and optimize it using two simulated datasets of time since convection, one based on meteorology, and the other on chemistry. The chemistry surrogate for time since convection is calculated using seven different chemical mechanisms, all of which predict shorter time since convection than our meteorological analysis. We evaluate chemical simulations by inter-comparison and by pairing results with observations based on $\mathrm{NO}_{\mathrm{x}}: \mathrm{HNO}_{3}$, a photochemical aging indicator. Inter-comparison reveals individual chemical mechanism biases and recommended updates. Evaluation against observations shows that all chemical mechanisms overpredict $\mathrm{NO}_{\mathrm{x}}$
\end{abstract}

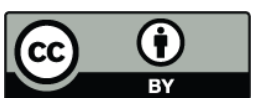

Correspondence to: $\mathrm{B}$. H. Henderson (barronh@gmail.com) removal relative to long-lived methanol and carbon monoxide. All chemical mechanisms underpredict observed $\mathrm{NO}_{\mathrm{x}}$ by at least $30 \%$, and further evaluation is necessary to refine simulation sensitivities to initial conditions and chemical rate uncertainties.

\section{Introduction}

Total oxidized nitrogen $\left[\mathrm{NO}_{\mathrm{y}}=\mathrm{NO}+\mathrm{NO}_{2}+\mathrm{NO}_{3}+\mathrm{N}_{2} \mathrm{O}_{5}+\right.$ $\mathrm{HNO}_{2}+\mathrm{HNO}_{3}+\mathrm{HO}_{2} \mathrm{NO}_{2}+\mathrm{CH}_{3}\left(\mathrm{CH}_{2}\right)_{\mathrm{n}} \mathrm{C}(\mathrm{O}) \mathrm{OONO}_{2}+$ $\mathrm{RNO}_{3}$ ] includes many compounds with a wide variety of physical properties and environmental roles. Nitrogen oxides $\left(\mathrm{NO}_{\mathrm{x}}=\mathrm{NO}+\mathrm{NO}_{2}\right)$ are water insoluble, chemically reactive in the atmosphere, and serve as precursors to ozone. Peroxy nitrates $\left(\mathrm{PNs}=\mathrm{HO}_{2} \mathrm{NO}_{2}+\mathrm{CH}_{3}\left(\mathrm{CH}_{2}\right)_{\mathrm{n}} \mathrm{C}(\mathrm{O}) \mathrm{OONO}_{2}\right)$ are insoluble, their chemical reactivity is temperature dependent, and they act primarily as a reservoir for $\mathrm{NO}_{\mathrm{x}}$. Nitric acid, on the other hand, is highly water soluble, chemically stable, and is a primary component of acid rain. The partitioning of the $\mathrm{NO}_{\mathrm{y}}$ between component compounds is controlled by a mix of physical (i.e., emissions and transport) and chemical (i.e., aqueous, particle, and gas-phase) processes and is critical to accurate simulation of environmental stress. The partitioning between $\mathrm{NO}_{\mathrm{y}}$ compounds influences the efficiency of $\mathrm{NO}_{\mathrm{y}}$ wet scavenging, the availability of $\mathrm{HNO}_{3}$ for acid rain, and the amount of $\mathrm{NO}_{\mathrm{x}}$ for production of the greenhouse gas ozone. As a greenhouse gas, ozone is 10 times more efficient in the upper troposphere than in the lower troposphere (Lacis et al., 1990). The upper troposphere, with its high ozone mixing ratio and high radiative

Published by Copernicus Publications on behalf of the European Geosciences Union. 
forcing efficiency, is also where chemical transport models (CTMs) underpredicted the $\mathrm{NO}_{\mathrm{x}}$ precursor (Napelenok et al., 2008; Bertram et al., 2007; Singh et al., 2007; Napelenok et al., 2008).

Underprediction of upper tropospheric $\mathrm{NO}_{\mathrm{x}}$ could be caused by any of the interrelated chemical and physical processes in CTMs that affect $\mathrm{NO}_{y}$ partitioning. Increasing simulated $\mathrm{NO}_{\mathrm{x}}$ from aircraft and lightning increase $\mathrm{NO}_{\mathrm{x}}$ mixing ratios, but does not resolve the bias. Pickering et al. (2009) found that lightning improved $\mathrm{NO}_{\mathrm{x}}$, but most bias improvement was below $8 \mathrm{~km}$. Hudman et al. (2007) concluded that lightning emissions improved simulated $\mathrm{NO}_{\mathrm{x}}$ mixing ratios, but the median simulated $\mathrm{NO}_{\mathrm{x}}$ mixing ratio was still $300 \mathrm{ppt}$ low-biased and the primary chemical sink $\left(\mathrm{HNO}_{3}\right)$ was now overpredicted. Other emission studies have quantified $\mathrm{NO}_{\mathrm{x}}$ emissions from aircraft (Eyers et al., 2004; Sutkus et al., 2003), which are generally small compared to lightning except perhaps directly in particular flight paths (Hudman et al., 2007). Zero dimensional modeling studies have suggested either missing observations or errors in chemical transformation of radical precursors in the upper troposphere (Olson et al., 2006; Ren et al., 2008). Emissions, physics, and chemistry both contribute to the $\mathrm{NO}_{\mathrm{x}}$ mixing ratios, requiring evaluation of each process in isolation.

This study develops and implements a new evaluation technique designed to isolate simulated chemistry in the upper troposphere. Chemistry evaluation, to date, uses either smog chamber experiments or quasi-Lagrangian measurements. Smog chamber experiments provide a direct evaluation in a controlled environment, but chamber experiments are carried out at surface level temperatures and pressures ( $T \approx 298 \mathrm{~K}, P \approx 1 \mathrm{~atm}$ ) and typically high $\mathrm{NO}_{\mathrm{x}}$ mixing ratios $\left(\mathrm{NO}_{\mathrm{x}}>50 \mathrm{ppb}\right)$, which are significantly different from the upper troposphere (medians from this study: $T=240 \mathrm{~K}$, $\left.P=0.31 \mathrm{~atm}, \mathrm{NO}_{\mathrm{x}}=0.4 \mathrm{ppb}\right)$. Quasi-Lagrangian aircraft measurements can provide temperature/pressure appropriate time-series case studies, but the Lagrangian nature of the sampling is often difficult to verify given uncertainty in meteorology (Real et al., 2008). Smog chamber evaluations do not have appropriate environmental conditions, and quasiLagrangian sampling does not provide enough high-quality samples for statistical evaluation. Any upper tropospheric evaluation must account for both environmental conditions and air parcel interaction with meteorology.

We propose a statistically robust chemical evaluation using in situ upper tropospheric aircraft observations from the Intercontinental Chemical Transport Experiment (INTEX-NA; Singh et al., 2006). Although these aircraft measurements do not sample a single air parcel through space and time, the measurements can be grouped and sorted by photochemical age using a technique developed by Bertram et al. (2007). This technique assumes that the "youngest" air parcels are the result of deep convection events. Deep convection mixes air from the earth's surface into the upper troposphere and is generally associated with precipitation that removes water soluble $\mathrm{HNO}_{3}$, but not less soluble $\mathrm{NO}_{\mathrm{x}}$ (Prather and Jacob, 1997; Jaeglé et al., 1998). Thus air parcels immediately following convection have very high ratios of $\mathrm{NO}_{\mathrm{x}}: \mathrm{HNO}_{3}$. After deep convection, air parcels undergo chemical processing that converts $\mathrm{NO}_{\mathrm{x}}$ to $\mathrm{HNO}_{3}$, reducing the $\mathrm{NO}_{\mathrm{x}}: \mathrm{HNO}_{3}$ ratio until the air parcel is removed from the upper troposphere by convective downdrafts or subsidence. Initial deep convection is identified by high $\mathrm{NO}_{\mathrm{x}}: \mathrm{HNO}_{3}$ and subsequent removal is modeled stochastically. Therefore, the observed $\mathrm{NO}_{\mathrm{x}}: \mathrm{HNO}_{3}$ ratio provides a relative metric of time since convection that can be used to create a time-series. This timeseries is suitable for evaluating chemistry in the upper troposphere because it has appropriate environmental conditions and enough observations for statistical evaluation.

This study uses a relative time-series of observations to evaluate photochemical aging predicted by seven different chemistry representations. Each chemistry representation, called a chemical mechanism, uses reaction sets with varying degrees and methods of simplification (Dodge, 2000). We selected seven chemical mechanisms from chemical transport models with spatial scales ranging from point to global. The complexity of each chemical mechanism also ranges from near-explicit to condensed. Near-explicit chemical mechanisms represent all known chemical compounds and reactions. Although all known reactions are included, many reactions have large uncertainty in the rate coefficient and stoichiometric yield. Condensed mechanisms use abstractions to reduce the computational load, but often include empirical tuning for conditions that may limit the applicability of the mechanism to all environmental conditions.

We evaluate each chemical mechanism to test three main questions. First, is the rate of chemical aging consistent between chemical mechanisms and observations? Second, are biases consistent for all chemical mechanisms, and therefore, fundamental to the state of the science, or can mechanism differences identify misrepresentations? Third, to what extent can chemical mechanisms' photochemical aging cause underprediction of $\mathrm{NO}_{2}$ ? Finally, we evaluate factors that contribute to partitioning biases for total oxidized nitrogen in an attempt to improve the individual chemical mechanisms.

\section{Methods}

\subsection{Modeling framework}

This study simulates photochemical aging and physical processing of air parcels following deep convection. Deep convection mixes lower tropospheric air with VOCs and $\mathrm{NO}_{\mathrm{x}}$ into upper tropospheric air (Bertram et al., 2007). Deep convection produces clouds that scavenge water soluble $\mathrm{HNO}_{3}$ and lightning that produces $\mathrm{NO}_{\mathrm{x}}$. These two processes result in high $\mathrm{NO}_{\mathrm{X}}: \mathrm{HNO}_{3}$ ratios that can identify air parcels transported by recent convection. After convection, the air parcel photochemically ages, converting $\mathrm{NO}_{\mathrm{x}}$ to $\mathrm{HNO}_{3}$, and 
mixes with background upper tropospheric air until it is removed from the upper troposphere by convective downdrafts or subsidence. Particle chemistry is most likely of limited importance in our study due to low particle surface area. In an initial analysis, less than $1 \%$ of $\mathrm{HNO}_{3}$ is in the particle phase at equilibrium. Aircraft observe air parcels at varying time since convection and, therefore, with varying extents of photochemical aging. We then developed a model to reproduce the observed distribution of photochemical age. To reproduce the distribution of air parcels, our model framework simulates gas-phase chemistry, photolysis, mixing into background air (i.e., dilution, dispersion, diffusion), and subsequent convection. Subsequent convection is caused by meteorological processes external to our box model, and we simulate this process stochastically using a distribution of time between convective influence. First, we simulate $10 \mathrm{~d}$ of chemical aging, or air parcel lifetime, for a variety of physical and chemical conditions representative of recently convected air parcels in the INTEX-NA observational database. In the real environment, we expect that air parcel lifetimes have a distribution that is governed by subsequent convection. We stochastically simulate subsequent convection by optimizing the distribution of air parcel lifetimes for consistency with observed chemical mixing ratios. The air parcel lifetimes can be evaluated against the empirical distribution, and the predicted distribution of chemical species during the air parcel lifetime can be compared to observed mixing ratios.

\subsection{Observations}

Aircraft observations provide box model initial conditions and photochemical age needed for model evaluation. We first sorted observations using $\mathrm{NO}_{\mathrm{x}}: \mathrm{HNO}_{3}$ as a chemical indicator of photochemical age. The measurements with the highest $\mathrm{NO}_{\mathrm{x}}: \mathrm{HNO}_{3}$ ratios provide physical conditions and initial chemical mixing ratios for model simulations using seven chemical mechanisms. The predictions are then evaluated against the observational time-series to assess the performance of simulated chemistry.

We use aircraft observations from the National Aeronautics and Space Administration (NASA) DC-8 aircraft flights during Intercontinental Chemical Transport Experiment North America (INTEX-NA) campaign (Singh et al., 2006). We started with the 10-s averaged NASA DC-8 observation database $(n=56465)$. We then filtered the observation database to include only measurements of the upper troposphere $(8 \mathrm{~km}<$ altitude $<10 \mathrm{~km})$. We exclude air parcels with any fractional cloud presence that would have active wet scavenging, which would influence $\mathrm{NO}_{\mathrm{x}}: \mathrm{HNO}_{3}$. We also removed air parcels that might have been influenced by stratospheric intrusion $\left({ }^{7} \mathrm{Be}:{ }^{210} \mathrm{~Pb}>1000\right)$ or biomass burning $\left(\mathrm{CH}_{3} \mathrm{CN}>200 \mathrm{ppt}\right)$. The remaining observations fall into two distinct groups: those influenced by polluted air $(\mathrm{CO} \geq 80 \mathrm{ppb})$ and those influenced by background air $(\mathrm{CO}<80 \mathrm{ppb})$ (Singh et al., 2007). Our analysis has been performed with both polluted and background influenced observations and excluding background observations. Both analyses give similar results. In this study, we focused on the influence of polluted air and include only those air parcels with over $80 \mathrm{ppb}$ CO $(n=861)$. These observations represent upper troposphere air parcels with varying photochemical age.

Observations of $\mathrm{NO}$ and $\mathrm{HNO}_{3}$ in the INTEX-NA dataset have known uncertainties and limitations that require adjustment. The NO chemiluminescence measurement has a long 1-minute integration time, is most reliable for mixing ratios greater than $100 \mathrm{ppt}$ (Singh et al., 2007) and, during the INTEX-NA campaign, has a strong bias compared to steady-state $\mathrm{NO}\left([\mathrm{NO}]_{\mathrm{SS}}=j_{\mathrm{NO}_{2}}\left[\mathrm{NO}_{2}\right] /\left(k_{\mathrm{O}_{3}+\mathrm{NO}}[\mathrm{O} 3]+\right.\right.$ $\left.k_{\mathrm{HO}_{2}+\mathrm{NO}}\left[\mathrm{HO}_{2}\right]\right)$. For this analysis, we require finer time resolution and detection of low NO $\left(17.7 \%\right.$ of $[\mathrm{NO}]_{\text {ss }}$ observations are below $100 \mathrm{ppt}$ ), so we use the steady-state calculated mixing ratio. During the INTEX-NA study, the University of New Hampshire (UNH) and the California Institute of Technology (CIT) took two separate measurements of $\mathrm{HNO}_{3}$. When observations are available simultaneously between 8 and $10 \mathrm{~km}$, the linear least squares fit of UNH as a function of CIT is $61.7 \%$. The reason for the discrepancy is currently unknown, so we and other researchers (Bertram et al., 2007) adjust UNH by a factor of 1.2 and CIT by a factor of 0.8. The CIT measurement has better time resolution, but less temporal coverage. We use the adjusted CIT measurement when available and fill in measurement gaps with the adjusted UNH measurement. The large discrepancy in the $\mathrm{HNO}_{3}$ measurement could bias our chemical surrogate of age. As a result, we have performed this analysis using CIT, UNH, and the adjusted $\mathrm{HNO}_{3}$ values (see Appendix). The conclusions of this study are robust to the choice of $\mathrm{HNO}_{3}$ measurement. Since the cause of the discrepancy is unknown, we use the adjusted values in the rest of this analysis.

The upper troposphere observations are then divided into age groups according to photochemical age as assessed by $\mathrm{NO}_{\mathrm{x}}: \mathrm{HNO}_{3}$. The observed $\mathrm{NO}_{\mathrm{x}}: \mathrm{HNO}_{3}$ ratio in our filtered dataset is log-normally distributed, and we split observations into 4 age groups that are non-overlapping, have comparable sample sizes, and capture the range of air parcel aging. The age groups, which represent relative photochemical age, will be referred to as fresh, young, midage, or old. Each category has a minimum of 215 observations (fresh: 216, young: 215, midage: 215, old: 215). An additional classification, "initial", was added to capture immediate convection for model initialization. The initial age group includes the youngest $50 \%$ of the fresh observations and represents air parcels that have been convected most recently. Figure 1 shows the total oxidized nitrogen $\left(\mathrm{NO}_{\mathrm{y}}\right)$ partitioning of each age group and shows that pernitric acid, PANS, and organic nitrates did not show strong age-dependent mixing ratios. 


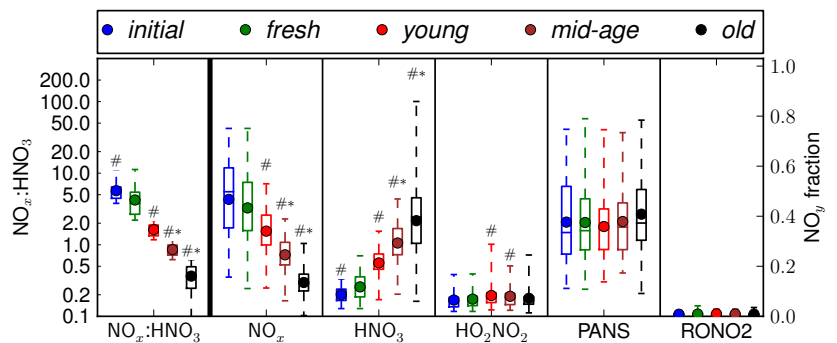

Fig. 1. Nitrogen partitioning of fresh, young, midage and old age categories demonstrates influence of chemical aging. Each age category has been tested for statistical difference $(p<0.0001)$ from the preceding age category $(*)$ and fresh $(\#)$.

\subsection{Box model}

We use a common box model framework for all simulations to remove artifacts of multiple modeling systems and isolate differences between seven chemical mechanisms. The use of a common box model removed variability in ordinary differential equation solvers and physical representations. The Dynamically Simple Model of Atmospheric Chemical Complexity (DSMACC) provided the flexibility and power necessary to model all our chemical mechanisms. The DSMACC model (Emmerson and Evans, 2009) is based on the Kinetic Pre-Processor (KPP) (Sandu and Sander, 2005), which has a flexible rate coefficient representation. The flexible rate representation allowed all seven chemical mechanisms to use their native reaction rate coefficient forms. We have added a mixing process to the DSMACC model to account for dilution, dispersion, and diffusion. Air parcels mix in "background" air where each chemical species mixing ratio is the mean of observations described above. The "background" air includes air parcels influenced by both polluted and background air. The rate of mixing is assumed to be constant and set to 5\% per day (Bertram et al., 2007). Sensitivity analysis using up to 10 times the mixing rate, and/or more complex dynamic background and dynamic mixing rates did not yield meaningfully different results (see Fig. A3). This box model represents only gas-phase chemical reactions and mixing with background air; there is no particle or aqueous chemistry.

\subsection{Gas-phase chemistry}

This study evaluates gas-phase chemistry from seven chemical mechanisms that each have different research goals. Carbon Bond version 2005 (Yarwood et al., 2005) and the State Air Pollution Research Center '99 (SAPRC99) (Carter, 2000) are typically used for urban to continental simulation. In addition, SAPRC '07 (Carter, 2009) and Regional Atmospheric Chemical Mechanism version 2 (RACM2) (Stockwell et al., 2008; Goliff and Stockwell, 2008; Goliff et al., 2011) are mechanisms that are planned to be included in the Environmental Protection Agency's Community Multiscale Air Quality model. The Goddard Earth Observing System-Chemistry (GEOS-Chem) (Mao et al., 2009) and Model for OZone And Related chemical Tracers (MOZART4) (Emmons et al., 2010) are typically used for global simulation. The near-explicit LEEDS Master Chemical Mechanism (MCM) (Saunders et al., 1997) is typically used in box model or trajectory simulations. For MCM, we extracted only those chemical reactions that would be active given our initial conditions and subsequent chemical products. The seven chemical mechanisms we evaluate are used for a range of research goals and have a range of computational complexity (see reactions and species in Table 1).

\subsection{Photolysis}

Gas-phase chemistry simulations typically use different photo-dissociation models that strongly influence radical initiation and photochemical cycling. Each chemical mechanism evaluated in this study is typically used in a host chemical transport model (i.e., CMAQ, GEOS-Chem, MOZART4, and SBOX) with specific photolysis models to calculate photo-dissociation rates. For example, Carbon Bond and SAPRC chemical mechanisms both used the CMAQ photolysis preprocessor (JPROC), GEOS-Chem used FAST-J photolysis (Wild et al., 2000), MCM used the Tropospheric Ultraviolet model (TUV) version 4.2 (Madronich, 2002), RACM2 used a predecessor of TUV, and MZ4 used TUV version 4.6. Not all photolysis models have implemented pressure/temperature sensitivities and the resulting difference in photolysis rates dominated the nitrogen partitioning in our initial tests. Particularly, representation of carbonyl photolysis temperature/pressure dependence led to differences in PAN predictions and the representation of nearIR photolysis $\left(0.00001 \mathrm{~s}^{-1}\right.$ Murphy et al., 2004) of pernitric acid led to diverse predictions. The different photolysis rates were not a function of chemical mechanism, but rather of the photolysis model calculation. To truly focus on chemical mechanism differences, the photolysis rates were standardized using TUV v4.6 with modifications consistent with those used in DSMACC for MCM with one exception. All mechanisms except MCM had photolysis reactions for PAN and $\mathrm{HO}_{2} \mathrm{NO}_{2}$ and, for this analysis, $\mathrm{PAN}$ and $\mathrm{HO}_{2} \mathrm{NO}_{2}$ photolysis has been added to MCM.

\subsection{Base simulations}

Each chemical mechanism simulates chemical aging for each initial observed air parcels $\left(n_{i}=108\right)$. The initial air parcels were used as the initialization of all simulated physical and chemical conditions (see Table 2). The initial observations of chemical species were mapped to their appropriate chemical mechanism species. Where particular chemical compound measurement was not concurrently available, the median of all initial values for that compound was used. An additional 
Table 1. Overview of chemical mechanisms in this study.

\begin{tabular}{lrr}
\hline Chemical Mechanism (abbreviation) & \# Rxns & \# Spcs \\
\hline Carbon Bond '05 (CB05) & 176 & 62 \\
State Air Pollution Research Center '99 (SAPRC99) & 222 & 77 \\
State Air Pollution Research Center '07 (SAPRC07) & 691 & 153 \\
Model for OZone And Related chemical Tracers “Standard” (MZ4) & 196 & 86 \\
GEOS-Chem “full”' (GEOS-Chem) & 286 & 88 \\
Regional Atmospheric Chemistry Mech v.2 (RACM2) & 349 & 117 \\
Master Chemical Mechanism Active Subset (MCM) & 4685 & 1610 \\
\hline
\end{tabular}

Table 2. Median observed values for filtered initial $\left(n_{\mathrm{i}}=108\right)$ and background $\left(n_{\mathrm{bkg}}=1006\right)$ selected chemical compounds and physical conditions.

\begin{tabular}{|c|c|c|c|}
\hline Measured & Background & Initial & Principal Investigator \\
\hline Altitude & $8841 \mathrm{~m}$ & $9149 \mathrm{~m}$ & J. Barrick, NASA LaRC \\
\hline Pressure & $314.7 \mathrm{hPa}$ & $300.6 \mathrm{hPa}$ & \\
\hline Temperature & $241.1 \mathrm{~K}$ & $233.7 \mathrm{~K}$ & \\
\hline $\mathrm{HO}^{-}$ & $0.5396 \mathrm{pptv}$ & $0.6101 \mathrm{pptv}$ & $\begin{array}{l}\text { W. Brune, Pennsylvania State University; Adjusted according } \\
\text { to Ren et al. (2008) }\end{array}$ \\
\hline $\mathrm{HO}_{2}$ & $13.16 \mathrm{pptv}$ & $11.24 \mathrm{pptv}$ & \\
\hline $\mathrm{O}_{3}$ & $77.76 \mathrm{ppbv}$ & $70.61 \mathrm{ppbv}$ & M. Avery, NASA LaRC \\
\hline $\mathrm{NO}_{2}$ & $95.52 \mathrm{pptv}$ & $153.6 \mathrm{pptv}$ & R. Cohen, UC Berkeley \\
\hline $\mathrm{NO}$ & 203.3 pptv & $411.8 \mathrm{pptv}$ & Derived from $\mathrm{NO}_{2}, \mathrm{O}_{3}$, and $\mathrm{HO}_{2}$ \\
\hline $\mathrm{HNO}_{3}$ & $280.1 \mathrm{pptv}$ & $125.9 \mathrm{pptv}$ & $\begin{array}{l}\text { P. Wennberg, California Institute of Technology; R.'Talbot, } \\
\text { Univ. of New Hampshire; Adjusted following } \\
\text { Bertram et al. (2007) }\end{array}$ \\
\hline $\mathrm{HO}_{2} \mathrm{NO}_{2}$ & $82.00 \mathrm{pptv}$ & $67.80 \mathrm{pptv}$ & G. Huey, Georgia Institute of Technology \\
\hline $\mathrm{H}_{2} \mathrm{O}_{2}$ & $234.2 \mathrm{pptv}$ & $195.9 \mathrm{pptv}$ & $\begin{array}{l}\text { P. Wennberg, California Institute of Technology; B. Heikes, } \\
\text { Univ. of Rhode Island; Adjusted following Bertram et al. (2007) }\end{array}$ \\
\hline $\mathrm{CO}$ & $98.36 \mathrm{ppbv}$ & $108.0 \mathrm{ppbv}$ & G. Sachse, NASA LaRC \\
\hline $\mathrm{CH}_{4}$ & $1.789 \mathrm{ppmv}$ & $1.784 \mathrm{ppmv}$ & D. Blake, UC Irvine, and E. Atlas, Univ. of Miami \\
\hline $\mathrm{C}_{2} \mathrm{H}_{6}$ & $790.0 \mathrm{pptv}$ & $800.0 \mathrm{pptv}$ & \\
\hline $\mathrm{C}_{3} \mathrm{H}_{8}$ & $146.0 \mathrm{pptv}$ & $153.5 \mathrm{pptv}$ & \\
\hline $\mathrm{C}_{2} \mathrm{H}_{4}$ & $1.500 \mathrm{pptv}$ & 1.500 pptv & \\
\hline $\begin{array}{l}\text { Speciated alkyl } \\
\text { nitrates }\left(\mathrm{RNO}_{3}\right)\end{array}$ & $8.630 \mathrm{pptv}$ & $8.630 \mathrm{pptv}$ & \\
\hline $\mathrm{CH}_{2} \mathrm{O}$ & $174.5 \mathrm{pptv}$ & $437.0 \mathrm{pptv}$ & A. Fried, NCAR; B. Heikes, Univ. of Rhode Island \\
\hline $\mathrm{CH}_{3} \mathrm{C}(\mathrm{O}) \mathrm{H}$ & $83.80 \mathrm{pptv}$ & $117.5 \mathrm{pptv}$ & H. Singh, NASA ARC \\
\hline $\mathrm{CH}_{3} \mathrm{C}(\mathrm{O}) \mathrm{CH}_{3}$ & 1475.pptv & 1375.pptv & \\
\hline $\mathrm{CH}_{3} \mathrm{C}(\mathrm{O}) \mathrm{C}_{2} \mathrm{H}_{5}$ & $71.25 \mathrm{pptv}$ & $95.00 \mathrm{pptv}$ & \\
\hline PAN & $374.9 \mathrm{pptv}$ & $370.6 \mathrm{pptv}$ & \\
\hline $\mathrm{CH}_{3} \mathrm{C}(\mathrm{O}) \mathrm{OOH}$ & $172.8 \mathrm{pptv}$ & $226.1 \mathrm{pptv}$ & P. Wennberg, California Institute of Technology \\
\hline
\end{tabular}

simulation was generated using the initial age group median value of every chemical compound. Each chemical mechanism was used to simulate $10 \mathrm{~d}$ of chemical processing for each initial air parcel and the median air parcel $\left(n_{s}=n_{i}+1\right)$. Nighttime simulation results (i.e., solar zenith angles, $\theta$, higher than $75^{\circ}$ ) are ignored to be consistent with exclusively daytime observations (i.e., $8<\theta<75^{\circ}$ ).

\subsection{Stochastic convection model description}

Our simulations must take into account the frequent exchange between the upper and lower troposphere. Convective updrafts loft air parcels into the upper troposphere which are later removed from the upper troposphere by convective downdrafts or subsidence. The time between convective lofting and removal, hereafter air parcel lifetime $\tau_{\text {air }}$, can be used to calculate the instantaneous or sampled distribution 
of time since convection $\operatorname{Pr}(t)$ in the upper troposphere. To accurately represent observed upper tropospheric air parcels, we must derive the distribution of time since convection $\operatorname{Pr}(t)$ and subset our simulation results accordingly. We estimate the distribution of time since convection using a maximum likelihood technique with one stochastic model and two observationally-derived datasets of time since convection.

The stochastic model for the distribution of air parcel lifetimes and of time since convection $\operatorname{Pr}(t)$ are both exponential. From an air parcel's perspective, encountering a downdraft is a random and time independent event that will have an exponential distribution (Gallager, 1996). If the INTEXNA observations were an unbiased random sample, Eq. (1) would describe the distribution of observed time since convection, where $\overline{\tau_{\text {air }}}$ is the mean air parcel lifetime. The INTEX-NA observations, however, preferentially sampled freshly convective air parcels. Bertram et al. (2007) showed that $21.4 \%$ of air parcels had time since convection less than $6 \mathrm{~h}$, which is far greater than $12.5 \%$ of the sampling domain with convective activity during the INTEX-NA campaign. To approximately correct the sample bias, we increase the relative probability of sampling time since convection less than $6 \mathrm{~h}$ by a factor of 2. Equation (2) doubles the probability of sampling young $(t<6 \mathrm{~h})$ air parcels (real or simulated), and still has only one fitting parameter $\overline{\tau_{\text {air }}}$.

$\operatorname{Pr}(t)=\frac{1}{\overline{\tau_{\mathrm{air}}}} \exp \left(\frac{-t}{\overline{\tau_{\mathrm{air}}}}\right)$

$\operatorname{Pr}(t)= \begin{cases}\frac{1}{\kappa\left(2-\exp \left(\frac{-6}{\bar{\tau}_{\text {air }}}\right)\right)} \exp \left(\frac{-t}{\kappa}\right) & \text { if } t \leq 6 \\ \frac{1}{\overline{\tau_{\text {air }}}\left(2-\exp \left(\frac{-6}{\left.\overline{\tau_{\text {air }}}\right)}\right)\right.} \exp \left(\frac{-t}{\bar{\tau}_{\text {air }}}\right) & \text { if } t>6\end{cases}$

where $\kappa=\frac{-6}{\log \left(2 \exp \left(\frac{-6}{\overline{\tau_{\text {air }}}}\right)-1\right)}$ and $\overline{\tau_{\text {air }}} \geq 9$

We estimate $\overline{\tau_{\text {air }}}$ by fitting our statistical models (Eqs. 1 and 2) to two empirical estimates of INTEX-NA observed time since convection. First, we use back trajectory encounters with convection systems calculated by Fuelberg et al. (2007). Second, we use our statistical model with chemical mechanisms to reproduce $\mathrm{NO}_{\mathrm{x}}: \mathrm{HNO}_{3}$, a chemical indicator of time since convection. These two approaches, described in detail below, require different assumptions, rely on different models, and provide independent estimates of estimate $\overline{\tau_{\text {air }}}$.

Fuelberg et al. (2007) simulated back trajectories and estimated time since convection, which we use to optimize our statistical model. Fuelberg et al. (2007, Table 3) reported the cumulative distribution function (CDF) of time since convection event at intervals starting at $6 \mathrm{~h}$, and ending at $240 \mathrm{~h}$. At $240 \mathrm{~h}, 91.8 \%$ of observations had encountered convection, which leaves $8.2 \%$ of observations with unknown time since convection. As a conservative approach, we fit our time since convection model to both the reported and renormalized CDF and provide the range of results as the back trajectory estimate of $\overline{\tau_{\text {air }}}$. For both the original and renormalized dataset, we find the $\overline{\tau_{\text {air }}}$ (between 1 and $240 \mathrm{~h}$ ) that minimizes the sum of squared prediction error.

Chemical indicators of time since convection, such as $\mathrm{NO}_{\mathrm{x}}: \mathrm{HNO}_{3}$, provide a second dataset for determining $\overline{\tau_{\text {air }}}$. The chemical evolution of $\mathrm{NO}_{\mathrm{x}}: \mathrm{HNO}_{3}$ is reproducible by chemical simulations, using chemical mechanisms, and then subsetting results proportional to Eq. (2). We iteratively subset our base simulations according to the probability of time since convection for each possible $\overline{\tau_{\text {air }}}(1-240 \mathrm{~h})$. To maximize the size of each subset, we normalize the probability of time since convection to a percentage (exponential: Eq. 3, bias-corrected: Eq. 4) of simulations at each model output time. Each result subset is an ensemble of simulated $\mathrm{NO}_{\mathrm{x}}: \mathrm{HNO}_{3}$ with varying initial conditions and time since convection. We then selected the optimal $\overline{\tau_{\text {air }}}$ based on the agreement of the simulation ensemble $\mathrm{NO}_{\mathrm{x}}: \mathrm{HNO}_{3}$ with observed $\mathrm{NO}_{\mathrm{x}}: \mathrm{HNO}_{3}$.

$$
\begin{aligned}
& p(t)=\exp \left(\frac{-t}{\overline{\tau_{\text {air }}}}\right) \\
& p(t)= \begin{cases}\exp \left(\frac{-t}{\kappa}\right) & \text { if } t \leq 6 \\
\frac{\kappa}{\bar{\tau}_{\text {air }}} \exp \left(\frac{-t}{\overline{\tau_{\text {air }}}}\right) & \text { if } t>6\end{cases}
\end{aligned}
$$

where $\kappa=\frac{-6}{\log \left(2 \exp \left(\frac{-6}{\bar{\tau}_{\text {air }}}\right)-1\right)}$ and $\overline{\tau_{\text {air }}} \geq 9$

For each $\overline{\tau_{\text {air }}}$, we then evaluate the agreement of the simulation ensemble with observed $\mathrm{NO}_{\mathrm{x}}: \mathrm{HNO}_{3}$ using the non-parametric Anderson-Darling K-sample goodness-of-fit statistic (Scholz and Stephens, 1987). The Anderson-Darling test makes no assumptions about data distribution (i.e., skew, kurtosis, etc.), and is particularly sensitive on tails of data distributions. Further, the fit criterion $\left(A_{\mathrm{kaN}}^{2}\right)$ is inversely proportional to goodness-of-fit, which makes it ideal for optimization. For each chemical mechanism, we minimize the fit criterion to identify the optimal $\overline{\tau_{\text {air }}}$.

\subsection{Evaluation approach}

We derive $\overline{\tau_{\text {air }}}$ using one approach that relies on back trajectory simulation and another that depends on chemical simulation. Using the back trajectory dataset provides an estimate of $\overline{\tau_{\text {air }}}$ that depends on the accuracy of a meteorology model. Using the chemical mechanism approach provides an estimate of $\overline{\tau_{\text {air }}}$ that depends on the modeled $\mathrm{NO}_{\mathrm{x}}$ to $\mathrm{HNO}_{3}$ conversion. If these two approaches confirm each other, we gain confidence that the chemical mechanisms are photochemically aging at the same rate as observations. If these two approaches conflict, we further evaluate chemical simulation results for evidence that the chemical aging rate is consistent or inconsistent with observed mixing ratios. 
We evaluate simulation results, sampled by optimal $\overline{\tau_{\text {air }}}$, to test the consistency of chemical aging precursors and products. Chemical aging, here assessed by $\mathrm{NO}_{\mathrm{x}}: \mathrm{HNO}_{3}$, includes the net production or loss of all oxidation precursors and products. If the chemical aging is consistent with observations, other oxidation precursors and products should also be correctly predicted. Our null hypothesis is that, given the same amount of nitrogen oxidation, simulated and observed mixing ratios will be statistically similar for chemical species that were not used to optimize $\overline{\tau_{\text {air }}}$. The predicted distributions of mixing ratios for simulated and observed chemical species are statistically compared using a Mann-WhitneyWilcoxon rank sum test (hereafter rank sum test) (Mann and Whitney, 1947). The rank sum test compares the entire distribution (i.e., not just the mean, median or mode) to test if one is statistically greater than the other. The rank sum test is a non-parametric test and, as such, makes no assumptions about data distribution (i.e., skew, kurtosis, etc). There is no perfect comparison between simulated and measured chemical mixing ratios. For instance, the aircraft observations are time $(10 \mathrm{~s})$ and space $(1.5$ to $3 \mathrm{~km})$ averaged while predictions are instantaneous. The averaging of observations could smooth out some extremes; this is especially true for fast reacting radical species (Olson et al., 2006). To account for some anticipated variation, this study requires a very high degree of confidence to conclude that observations are distinct from model mixing ratios. We only reject the null hypothesis if the probability of the difference in distributions is less than $0.01 \%(p<0.0001)$.

\section{Results}

\subsection{Stochastic convection: back trajectory results}

The back trajectory estimation technique has four discrete estimates of mean air parcel lifetime $\left(\overline{\tau_{\text {air }}}\right)$. Each estimate comes from combining a time since convection dataset, either the unadjusted or renormalized, and a statistical model, either the exponential (Eq. 1) or bias-corrected (Eq. 2) as described in the Stochastic Model Description. Figure 2 shows that renormalizing the back trajectory dataset shortens the $\overline{\tau_{\text {air }}}$ estimate, while using the bias-corrected statistical model lengthens the $\overline{\tau_{\text {air }}}$ estimate. Both the renormalized dataset and the bias-corrected statistical model incrementally improve the coefficient of correlation $\left(R^{2}\right)$. Using the unadjusted back trajectory results, the exponential model (a) predicts $\overline{\tau_{\text {air }}}=40 \mathrm{~h}$ and our bias-corrected model (b) predicts $\overline{\tau_{\text {air }}}=51 \mathrm{~h}$. With renormalized back trajectory results, the exponential model (c) predicts $\overline{\tau_{\text {air }}}=47 \mathrm{~h}$ and our biascorrected model (d) predicts $\overline{\tau_{\text {air }}}=58 \mathrm{~h}$.

\subsection{Stochastic convection: $\mathrm{NO}_{\mathrm{x}}: \mathrm{HNO}_{3}$ results}

The chemical mechanism technique of estimating of $\overline{\tau_{\text {air }}}$ consistently yielded shorter $\overline{\tau_{\text {air }}}$ values than the back trajectory approach. Figure 3 compares the back trajectory and chemi-

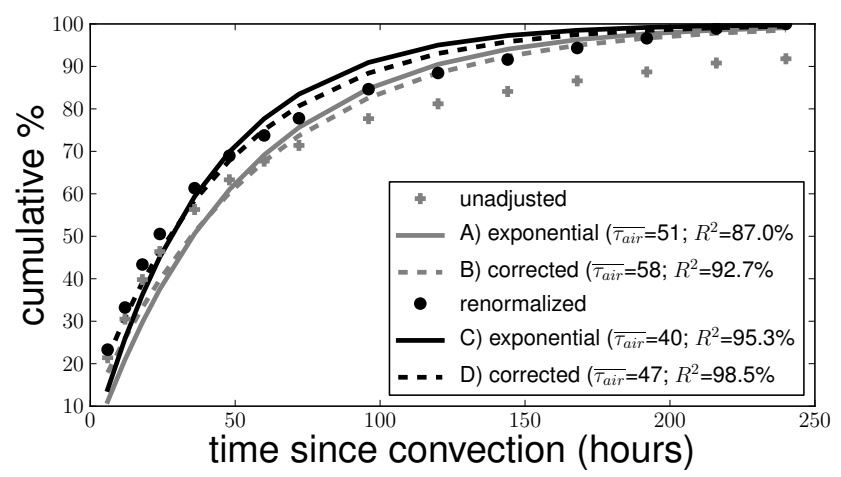

Fig. 2. Optimization results for stochastic convection using the exponential and bias-corrected statistical model with the unadjusted and renormalized back trajectory dataset. (A) exponential model (Eq. 1) with unadjusted dataset; (B) bias-corrected model (Eq. 2) with renormalized dataset; $(\mathbf{C})$ exponential model with unadjusted dataset; (D) bias-corrected model with renormalized dataset.

cal mechanism $\overline{\tau_{\text {air }}}$. The shortest $\overline{\tau_{\text {air }}}$ estimates for all chemical mechanisms was derived using the exponential model (18-23 h). When using the optimized exponential model (Eq. 3), all chemical mechanisms, except SAPRC99 and RACM2, predicted $\mathrm{NO}_{\mathrm{x}}: \mathrm{HNO}_{3}$ ratios that are statistically different from observations. When the convection model is corrected for sampling bias (Eq. 4), estimated air parcel lifetimes are longer $(28-34 \mathrm{~h})$ and $\mathrm{NO}_{\mathrm{x}}: \mathrm{HNO}_{3}$ compares better with observations. When correcting for sampling bias, Fig. 4 shows that all the chemical mechanisms capture the general shape of the observed $\mathrm{NO}_{\mathrm{x}}: \mathrm{HNO}_{3}$. As a result, the Anderson-Darling goodness-of-fit test cannot reject the null hypothesis that $\mathrm{NO}_{\mathrm{x}}: \mathrm{HNO}_{3}$ is consistent with observations $(\alpha<0.01)$. Even though the chemical mechanisms capture the distribution of observed $\mathrm{NO}_{\mathrm{x}}: \mathrm{HNO}_{3}$, the highest $\overline{\tau_{\text {air }}}$ estimate is $6 \mathrm{~h}$ shorter than the shortest back trajectory estimate.

The back trajectory estimates of time since convection are all longer than any estimate by chemical mechanisms. If any of the back trajectory $\overline{\tau_{\text {air }}}$ estimates are correct, all of the chemical mechanisms too rapidly remove $\mathrm{NO}_{\mathrm{x}}$. Because $\mathrm{NO}_{\mathrm{x}}$ components $\mathrm{NO}$ and $\mathrm{NO}_{2}$ are in steady state, this leads to an underprediction of $\mathrm{NO}_{2}$. We estimate the $\mathrm{NO}_{2}$ low-bias by sampling simulated results using our statistical model of convection optimized with back trajectory time since convection. Even when we sample the simulation results using the lowest $\overline{\tau_{\text {air }}}$ estimate $\left(40 \mathrm{~h}\right.$ ), we underpredict $\mathrm{NO}_{2}$ by at least $30 \%$.

\subsection{Chemical mixing ratio evaluation}

The chemical mechanism and back trajectory $\overline{\tau_{\text {air }}}$ estimates disagree, suggesting a need to further evaluate predicted oxidation precursors and products. We evaluate oxidation precursors and products to assess our confidence in the chemical mechanism estimate and to understand chemical mechanism 


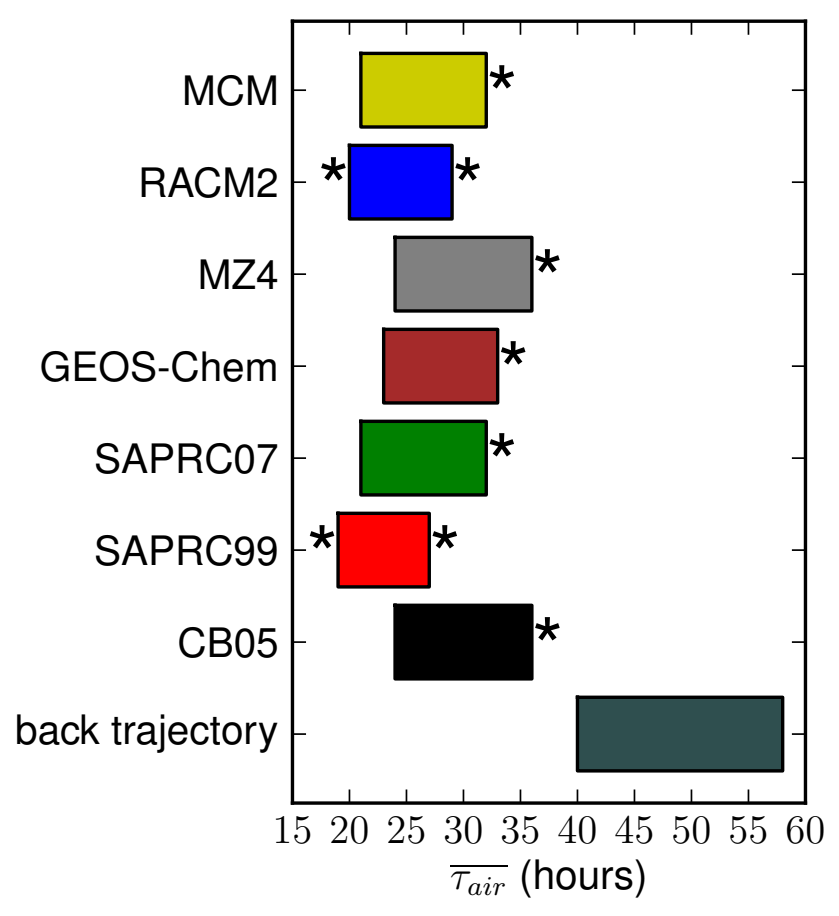

Fig. 3. Range of estimated mean air parcel lifetimes $\left(\overline{\tau_{\text {air }}}\right)$ derived from back trajectory and chemical simulation. Asterisks indicate whether chemically simulated $\mathrm{NO}_{\mathrm{x}}: \mathrm{HNO}_{3}$ is statistically consistent with observations $(\alpha<0.01)$ when using the exponential (left, Eq. 3) and bias-corrected (right, Eq. 4) statistical models.

differences. For the chemical evaluation, we use the biascorrected convection (Eq. 4) because it produces the longest $\overline{\tau_{\text {air }}}$ and, therefore, is the most conservative comparison. Figure 5 overlays simulation ensemble predictions over observations for selected chemical species illustrating chemical mechanism biases. For each chemical species, Fig. 5 shows the distribution of predictions and observations for the five age groups. Figure 5 also denotes observed statistically significant trends between age groups and statistically significant biases in chemical mechanism predictions (see caption for details). For each chemical mechanism, the median is a circle that is hollow when simulations are statistically biased compared to observations. The statistical biases demonstrate that some problems are mechanism-specific, while others affect all tested mechanisms.

Given the same amount of nitrogen aging or oxidation, we expect other oxidation products to compare well. The oxidation products ozone and hydrogen peroxide, however, were only well-predicted until the midage age group. For ozone, SAPRC99 underpredicts midage and old mixing ratios. For hydrogen peroxide, SAPRC99, SAPRC07, and GEOS-Chem underpredict as early as the midage age group. By the old age group, all chemical mechanisms now under-predict hydrogen peroxide.
Given the same amount of nitrogen aging, we also expect oxidation precursors to compare well. Chemical mechanisms, however, tended to underpredict quickly-reacting carbonyls acetaldehyde $\left(\mathrm{CH}_{3} \mathrm{CHO}\right)$ and peroxy acetic acid $\left(\mathrm{CH}_{3} \mathrm{C}(\mathrm{O}) \mathrm{OOH}\right)$ while overpredicting longer-lived species carbon monoxide $(\mathrm{CO})$ and methanol $\left(\mathrm{CH}_{3} \mathrm{OH}\right)$. Acetaldehyde observations, for example, showed no statistical trend, but the predicted mixing ratios decrease with time. All chemical mechanisms underpredict the acetaldehyde magnitude and inter-quartile range almost immediately. Peroxy acetic acid observations also had no statistically significant decrease with time, but predictions bias depended on the chemical mechanism. For peroxy acetic acid mixing ratios, the SAPRC99 mechanism overpredicted, SAPRC07, RACM2 and GEOS-Chem underpredicted, while MZ4 and CB05 performed statistically well. For longer lived carbon monoxide and methanol, all chemical mechanisms overpredicted as early as the young age group.

These long-lived species, particularly methanol $\left(\mathrm{CH}_{3} \mathrm{OH}\right)$ and carbon monoxide (CO), are important because they are alternative indicators of time. Methanol and carbon monoxide are lost exclusively by slow, well-known $\mathrm{OH}^{-}$reactions and have relatively little secondary chemical production in the upper troposphere. The bias in predicted carbon monoxide, when $\mathrm{NO}_{\mathrm{x}}: \mathrm{HNO}_{3}$ is used as a surrogate for time, is a clear discrepancy. The chemical mechanisms incrementally remove long-lived carbon as a function of integration time, but as a function of $\mathrm{NO}_{\mathrm{x}}: \mathrm{HNO}_{3}$ there is little integration time difference between age groups. As a result, long-lived carbon is relatively constant between age categories until the parcel is old.

\subsection{Chemical mechanism biases and recommendations}

In several cases, chemical mechanisms had striking biases that can be explained by either modeling assumptions or updates to the kinetic literature. The CB05 mechanism had by far the highest bias for organic nitrates $\left(\mathrm{RNO}_{3}\right)$, which can be explained by its representation of acetone. Both GEOSChem and RACM2 oxidized peroxy acetic acid much faster than the other chemical mechanisms, which can be explained by the choice of kinetic surrogate. All mechanisms overpredict peroxy nitric acid during the young age group, which can be improved by updating the $\mathrm{OH}$ rate constant. Each of these issues is explored in detail below, and implemented to see the change in estimated air parcel lifetime $\left(\overline{\tau_{\text {air }}}\right)$.

The CB05 simulations partition up to $25 \%$ of total nitrogen into $\mathrm{RNO}_{3}$, but all chemical mechanisms that explicitly represent acetone predict less than $3 \%$. The $\mathrm{RNO}_{3}$ production is a sink for both $\mathrm{HO}_{\mathrm{x}}$ and $\mathrm{NO}_{\mathrm{x}}$, decreasing availability of $\mathrm{OH}$ and $\mathrm{NO}_{2}$, which leads to $\mathrm{CB} 05$ predicting the lowest $\mathrm{HNO}_{3}$. The overprediction of $\mathrm{RNO}_{3}$ by CB05 is a result of structural lumping that combines acetone into the model species PAR. The CB05 PAR species holds all singly bonded carbon, but also holds all carbon from acetone (Yarwood et al., 


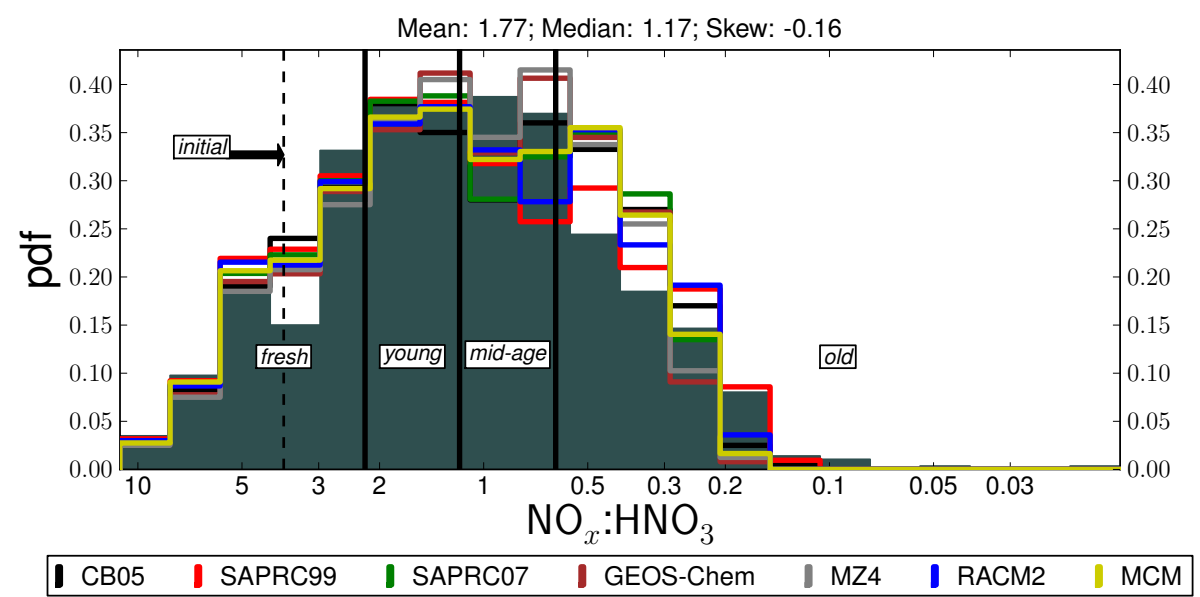

Fig. 4. Observed $\mathrm{NO}_{\mathrm{x}}: \mathrm{HNO}_{3}$ (bars) compared to simulated (lines) from each chemical mechanism using the optimized, bias-corrected statistical model.
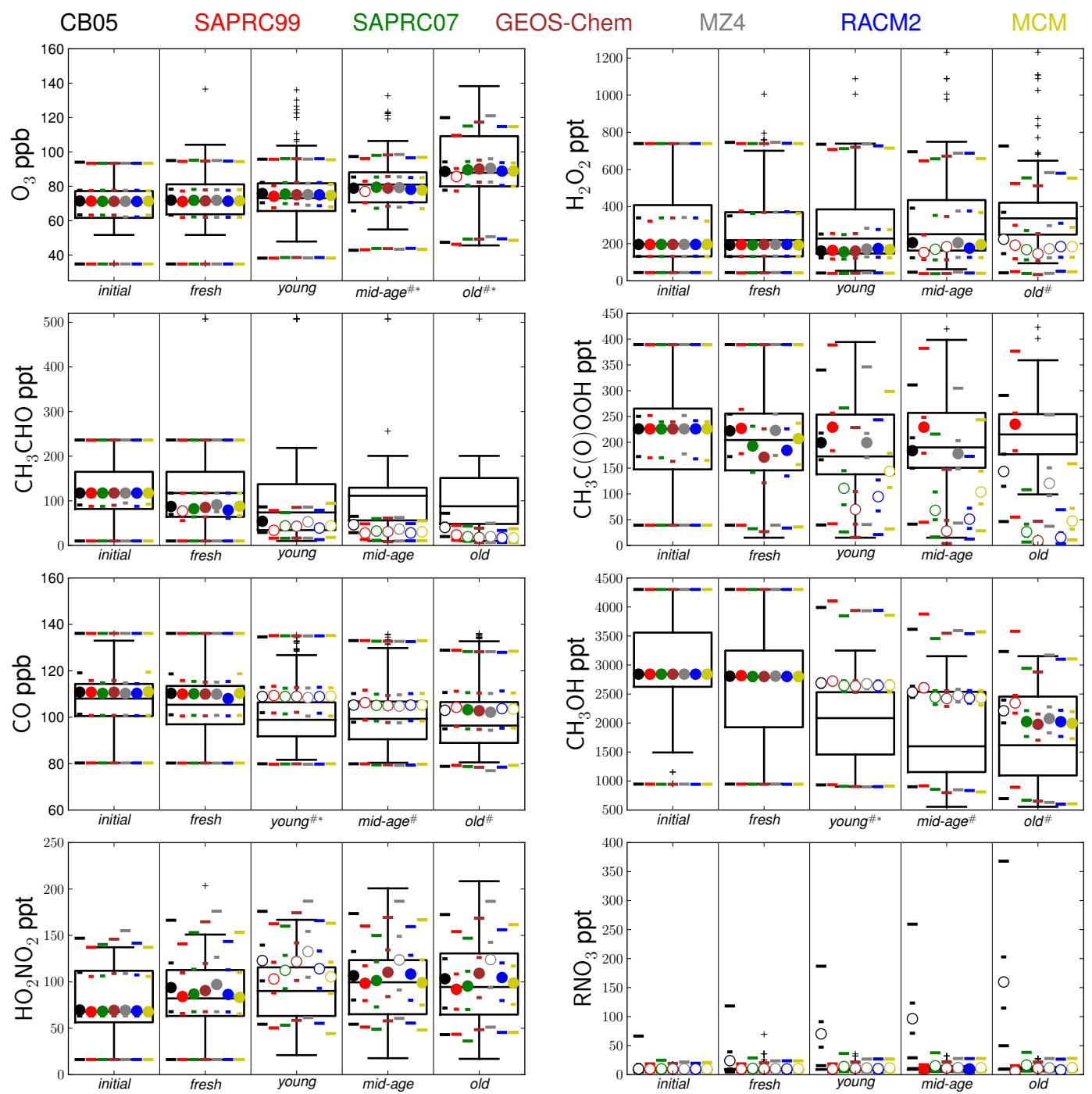

Fig. 5. Simulation results (circle: median; bars: $0,25,75,100$ percentiles) and observations (box and whisker) binned by $\mathrm{NO}_{\mathrm{x}}: \mathrm{HNO}_{3}$. For observations, each age category is superscripted for statistical difference $(p<0.0001)$ from the preceding $(*)$ and fresh (\#) age group. For model predictions, the median for each chemical mechanism is left hollow when statistically different $(p<0.0001)$ from the observations. 


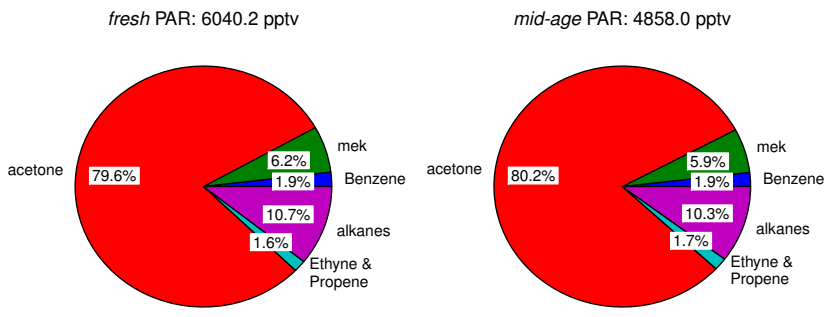

Fig. 6. Composition of CB05 PAR chemical mechanism species as measured during INTEX-NA in the median air parcel for fresh and young age groups.

2005). Acetone has a long lifetime and high mixing ratios in the upper troposphere, so it can dominate the carbon in PAR (see Fig. 6). The PAR + OH organic nitrate yield, however, is based on urban, surface PAR reactivity (i.e., primarily alkanes). In $\mathrm{CB} 05$, the $\mathrm{PAR}+\mathrm{OH}$ reaction creates an operator species $\left(\mathrm{XO}_{2} \mathrm{~N}\right)$, directly $(13 \%)$ and indirectly $(3 \%)$, that yield $>10 \%$ organic nitrates production. In contrast, explicit representation of acetone in GEOS-Chem yields 3.6\% organic nitrates. In the upper troposphere where acetone is the dominant PAR contributor, the organic nitrate fraction would have to be adjusted or acetone would need to be handled explicitly. A simple adjustment in CB05 of organic nitrate yield to $3 \%$ (as in GEOS-Chem) improves organic nitrate yield significantly and increases the $\overline{\tau_{\text {air }}}$ to $40 \mathrm{~h}$, which is also the lower bound back trajectory $\overline{\tau_{\text {air }}}$ estimate.

GEOS-Chem and RACM2 predict a median peroxy acetic acid $\left(\mathrm{CH}_{3} \mathrm{C}(\mathrm{O}) \mathrm{OOH}\right)$ mixing ratio less than the observed 25 th percentile by the young age group. Peroxy acetic acid is the second largest acyl peroxy radical source (i.e., PAN precursor) in the first $6 \mathrm{~h}$ of simulated aging. The primary loss pathway for peroxy acetic acid is reaction with $\mathrm{OH}^{\text {, }}$ but the $\mathrm{OH}^{-}$rate coefficient is not available in the literature. Both chemical mechanisms that underpredict peroxy acetic acid choose methyl peroxide as a surrogate compound for the $\mathrm{OH}$ rate coefficient. The chemical mechanisms that perform better, however, use the acetic acid $\mathrm{OH}^{-}$rate coefficient. At upper tropospheric temperature and pressure, the acetic acid rate coefficient reported by Sander et al. (2006) (not updated from 2003 report see errata) and Atkinson et al. (2006) are both roughly ten times lower than the methyl peroxide $\mathrm{OH}^{*}$ rate. Preliminary peroxy acetic acid $\mathrm{OH}^{\cdot}$ rate studies confirm the $\mathrm{k}_{\mathrm{OH}}$ similarity to $\mathrm{CH}_{3} \mathrm{C}(\mathrm{O}) \mathrm{OH}$ (Orlando and Tyndall, 2002).

Pernitric acid is overpredicted by all chemical mechanisms and acts as an important radical sink in the upper troposphere. In the upper troposphere, pernitric acid that is formed $\left(\mathrm{HO}_{2}+\mathrm{NO}_{2} \rightarrow \mathrm{HO}_{2} \mathrm{NO}_{2}\right)$ is thermally stable, and the primary loss is $\mathrm{OH}+\mathrm{HO}_{2} \mathrm{NO}_{2}$ (see Fig. 7). The net pernitric acid reaction consumes two $\mathrm{HO}_{\mathrm{x}}$ radicals (Wennberg et al., 1998) and, in this study, this net reaction accounts for $29 \%$ of the radicals terminated in the first $6 \mathrm{~h}$. We recommend us- ing the latest $k_{\mathrm{OH}}+\mathrm{HO}_{2} \mathrm{NO}_{2}$ (Jimenez et al., 2004) which improves $\mathrm{HO}_{2} \mathrm{NO}_{2}$ agreement with observations and increases competition of pernitric acid with $\mathrm{NO}_{2}$ for $\mathrm{OH}$ radicals. Even with this recommendation, the pernitric acid reaction rates have large uncertainties at low temperatures and laboratory studies are restricted to temperatures above those typical in the upper troposphere (Atkinson et al., 2004; Gierczak et al., 2005; Sander et al., 2006).

The peroxy acetic acid and peroxy nitrate recommendations implemented together into our working version of GEOS-Chem. These changes improve peroxy acetic acid and pernitric acid predictions, and increase the $\overline{\tau_{\text {air }}}$ estimate from 32 to $34 \mathrm{~h}$. The new predicted $\mathrm{NO}_{\mathrm{x}}: \mathrm{HNO}_{3}$ is now statistically consistent with observations at the $p<0.01$ level. Despite the improved $\mathrm{NO}_{\mathrm{x}}: \mathrm{HNO}_{3}$, the $\overline{\tau_{\text {air }}}$ estimate is still $6 \mathrm{~h}$ shorter than the lowest back trajectory estimate, and the marginally longer $\overline{\tau_{\text {air }}}$ has little affect on long-lived carbon.

\section{Discussion}

The evidence gathered here suggests that the chemical mechanisms photochemically age $\mathrm{NO}_{\mathrm{x}}$ too quickly. First, all chemical mechanism estimates of air parcel lifetime, the time necessary to age $\mathrm{NO}_{\mathrm{x}}$, are at least $15 \%$ shorter than the shortest back trajectory estimate. Second, the chemical mechanism air parcel lifetime estimates are insufficient to remove long-lived carbon, as seen in observations. Given these discrepancies, we conclude that chemical mechanisms will be low-biased for $\mathrm{NO}_{\mathrm{x}}$ in the upper troposphere at any given time since convection.

We investigated individual chemical mechanism biases to develop and test recommendations. Peroxy acetic acid, a peroxy acetyl nitrate precursor, is removed too quickly by chemical mechanisms that use methyl peroxide; we recommend all mechanisms use acetic acid as a surrogate until a specific rate is available. Peroxy nitrates are an important radical sink in the upper troposphere, and we recommend several updates. The primary peroxy nitrate loss reactions in the upper troposphere are photolysis and hydroxyl attack. For photolysis, we recommend that all chemical mechanisms include photolysis for PANs and pernitric acid, and that pernitric acid near IR photolysis be included. For hydroxyl attack, we recommend updating the $\mathrm{OH}^{\cdot}$ reaction rate (Jimenez et al., 2004). Finally, explicit or targeted parameterization of acetone is necessary to properly model radical cycling in the upper troposphere. Improved representation of acetone will decrease overpredictions of alkyl nitrates, which will alter radical cycling and total oxidation. The recommendations improved target species predictions and increased air parcel lifetime, but did not solve overpredictions of long-lived carbon.

This analysis included only gas-phase chemistry and ignores heterogeneous processing that also affects the $\mathrm{NO}_{\mathrm{x}}: \mathrm{HNO}_{3}$ ratio. Including $\mathrm{N}_{2} \mathrm{O}_{5}$ heterogeneous hydrolysis 

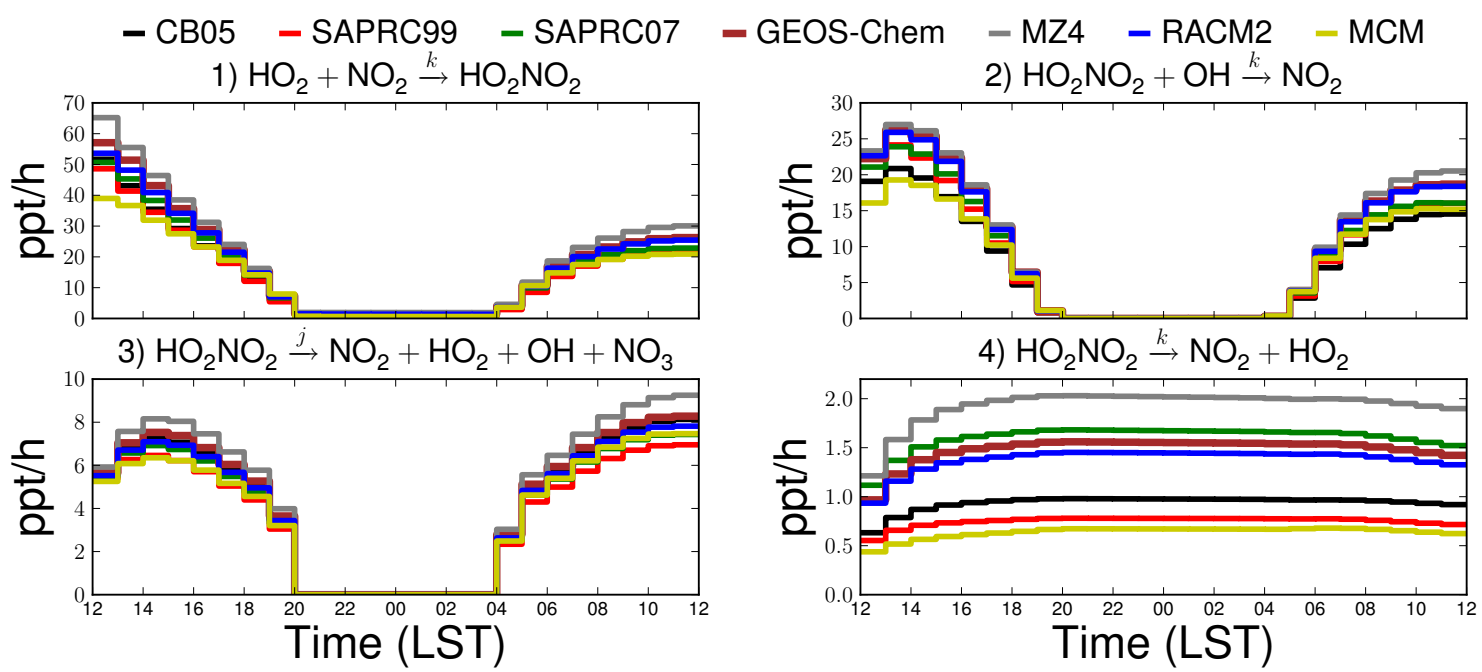

Fig. 7. Pernitric acid gross production and loss from the median air parcel.

would exacerbate the rate of $\mathrm{NO}_{\mathrm{x}}$ to $\mathrm{HNO}_{3}$ conversion (Jaeglé et al., 1998; Olson et al., 2001; Evans and Jacob, 2005). Mineral dust and ice particle uptake of $\mathrm{HNO}_{3}$ would buffer or counteract the effect of $\mathrm{N}_{2} \mathrm{O}_{5}$ hydrolysis. Our initial analysis of $\mathrm{HNO}_{3}$ uptake suggests that this rate would be small compared to nitric acid production $\mathrm{NO}_{2}+\mathrm{OH}$. We intend to evaluate heterogeneous processing in more depth along chemical rate analysis there.

During this study, several best practices for atmospheric chemical modeling became apparent. The chemical system is very sensitive to the photolysis rates, and so it is critical to simulate photolysis in a detailed way when evaluating the chemical mechanisms. Photolysis simulations need to represent up-to-date pressure/temperature sensitivities. For instance, two models evaluated for use in this study did not include temperature/pressure sensitivities, which are critical in the upper troposphere. To accurately simulate temperature/pressure sensitivities, photolysis rates need to be calculated at the chemical transport model vertical resolution. Photolysis rates of many species (e.g. ozone) exhibit complex shape throughout the troposphere and linear interpolation can drastically underpredict local minima and maxima. Coarse resolution in some photolysis preprocessors is most likely a hold over from historically coarser CTM vertical resolutions. Also, ensure that the chemical mechanism used accounts for PAN photolysis and near-IR $\mathrm{HO}_{2} \mathrm{NO}_{2}$ photolysis. Photolysis is the dominant PAN chemical loss process in the upper troposphere, where many have reported PAN overprediction (Pickering et al., 2009; Yu et al., 2010; Fang et al., 2010).

\section{Conclusions}

This study uses a new probabilistic approach to isolate simulated chemistry for evaluation in the upper troposphere. This approach uses a large number of observations for statistical power and parameterizes processes whose stochastic nature precludes box model simulation. Parameterizing all other processes isolates gas-phase chemistry and produces an ideal modeling system for evaluation in the upper troposphere. Other upper troposphere gas-phase evaluations rely on steady-state assumptions or quasi-Lagrangian measurements. Steady-state assumptions may not be valid in the upper troposphere because convective mixing constantly perturbs $\mathrm{NO}_{\mathrm{x}}$ and radical mixing ratios (Prather and Jacob, 1997). Quasi-Lagrangian analysis provides a direct evaluation approach when sufficient observations are available and their Lagrangian nature can be confirmed. Both the quasiLagrangian approach and our probabilistic approach have benefits that can complement each other to strengthen our body of knowledge where time-series observations from a single air parcel (e.g. smog chamber experiments) are not available.

One specific goal of this study was to characterize the contribution of chemistry to upper troposphere underprediction of $\mathrm{NO}_{2}$. The results presented here confirm previously reported $\mathrm{NO}_{2}$ underpredictions, and do so in an isolated chemistry model. All evaluated chemical mechanisms converted $\mathrm{NO}_{\mathrm{x}}$ to $\mathrm{HNO}_{3}$ too rapidly and, consequently, underpredicted $\mathrm{NO}_{2}$ by at least $30 \%$. Even if all emissions, physical transport, and aqueous-phase chemistry were accurately simulated by a chemical transport model, gas-phase chemistry would cause model underpredictions of $\mathrm{NO}_{2}$.

This paper isolates chemistry and establishes $\mathrm{NO}_{2}$ bias caused by chemistry. While this work does not resolve the problem, the modeling framework described provides a test 
Table A1. Optimization results for stochastic convection using the pure exponential model and the model with correction for preferential sampling. Table includes optimal air parcel lifetime $\left(\overline{\tau_{\text {air }}}\right)$ and Anderson Darling goodness-of-fit test value $\left(T_{\mathrm{kaN}}\right)$ for alternative background mixing rate sensitivities. The predicted $\mathrm{NO}_{\mathrm{x}}: \mathrm{HNO}_{3}$ is statistically different than observations when $T_{\mathrm{kaN}}$ is greater than $3.752(\alpha=0.01)$.

\begin{tabular}{lrrrr}
\hline \multirow{2}{*}{ Mechanism } & \multicolumn{2}{c}{ exponential } & \multicolumn{2}{c}{ corrected } \\
& $\overline{\tau_{\text {air }}}$ & $T_{\mathrm{kaN}}$ & $\overline{\tau_{\text {air }}}$ & $T_{\mathrm{kaN}}$ \\
\hline GEOS-Chem & 23 & 9.9 & 33 & 2.77 \\
$2 \times$ Mix & 21 & 10.6 & 32 & 3.62 \\
$4 \times$ Mix & 20 & 11.6 & 31 & 5.59 \\
$10 \times$ Mix & 18 & 15.9 & 28 & 10.2 \\
GC* & 24 & 8.32 & 36 & 2.28 \\
M10 $\times$ Init & 28 & 65.9 & 43 & 51 \\
DynMix & 24 & 7.42 & 36 & 2.28 \\
\hline
\end{tabular}

environment for further analysis. Initial analyses demonstrate that results presented here are robust to uncertainty in initial conditions, but that rate expression uncertainty can meaningfully slow chemical mechanism $\mathrm{NO}_{\mathrm{x}}$ aging. Future research will conduct sensitivity tests to identify key rate expressions. The results from subsequent sensitivity tests should be used to direct gas-phase rate research that will improve state of the science chemical mechanisms.

\section{A1 Observation}

The spatial distribution of all age groups (defined in the paper) are shown in Fig. A1.

\section{A2 Subsequent removal}

Upper troposphere air parcel lifetimes are limited by subsequently encountered convection and large scale subsidence. Air parcels in the UT subside along isentropic surfaces, but not as rapidly as they are removed by convection related processes (Prather and Jacob, 1997; Jaeglé et al., 1998). The importance of convection is most clear in the tropics where convection is very frequent. To confirm the importance of convection during the INTEX-NA, we simulated back trajectories a 12 locations forming a grid over the Northeastern United States using the Hybrid Single Particle Lagrangian Integrated Trajectory Model (HYSPLIT Draxler and Hess, 1997). During a $84 \mathrm{~h}$ (70\% of the time between INTEXNA convective events Fuelberg et al., 2007) back trajectory with only isentropic vertical motion, Fig. A2 shows that only 3 of the 12 simulations originated below $8 \mathrm{~km}$ or above $10 \mathrm{~km}$. This confirms our conceptual model of convection as the dominant removal process of air parcels from the upper troposphere.

\section{A3 Alternate background mixing scenarios}

Our analysis uses background mixing calculated by Bertram et al. (2007), but there are significantly higher literature values. Figure A3 shows 5 mixing sensitivity analysis. We test the sensitivity of our analysis by scaling our mixing parameter by 2,4 , and 10 . Standard mixing is $5 \%$ per day, so these scaling values evaluate to $10 \%, 20 \%$, and $50 \%$. Twenty percent is the upper bound of values found in the literature (Bertram et al., 2007, and references therein) and 50\% is used to demonstrate the influence of drastically increasing mixing. We also test the possibility of variable mixing efficiency and variable boundary conditions. This dynamic mixing test (DynMix) has mixing efficiency of $50 \%$ per day in the initial age group, $25 \%$ per day in the fresh age group, and $5 \%$ in midage and old age groups. These initial and fresh air parcels vigorously mix in chemical mixing ratios set by the air parcel's initial conditions. When the air parcel transitions to young age status, I decrease the mixing to $5 \times$ (also tried $6 \times)$ and start mix (1:1) of initial and background air, where background air is the average mixing ratio of all observations. When the air parcel transitions to midage, I return to the standard mixing rate and mix in "background" air. This is an extreme assumption because surrounding parcels should also be aging during the fresh time period. The air parcel lifetimes and the predicted $\mathrm{NO}_{\mathrm{x}}: \mathrm{HNO}_{3}$ evaluation are shown in Table A1.

\section{A4 Implications of measurement discrepancy for nitric acid}

The disagreement between $\mathrm{HNO}_{3}$ measured by CIT and UNH has the potential to influence our mean air parcel lifetime. The CIT and UNH measurements are not always coincident in time, so analysis using either has fewer total observations. When using just the CIT measurements, there are only 507 total observations and only 65 initial conditions. When using the UNH measurements, there are 842 total observations and 107 initial conditions. The CIT and $\mathrm{UNH}$ measurements both have log-normal distributions. The CIT distribution is broader and less smooth than the UNH distribution (see Fig. A4).

Our modeling framework is able to capture $\mathrm{NO}_{\mathrm{x}}: \mathrm{HNO}_{3}$ distribution using the UNH and CIT measurements. Both the UNH and CIT mean air parcel lifetimes ( $\tau_{\mathrm{UNH}}$ and $\left.\tau_{\mathrm{CIT}}\right)$ are shorter than predicted with adjusted values (see Fig. A5). Using the lower $\mathrm{UNH}$ measurements increases the $\mathrm{NO}_{\mathrm{x}}: \mathrm{HNO}_{3}$ values and shifts the $\mathrm{NO}_{\mathrm{x}}: \mathrm{HNO}_{3}$ age bin cut-points to higher values. Because the chemistry model tends to overpredict conversion of $\mathrm{NO}_{\mathrm{x}}$ to $\mathrm{HNO}_{3}$, the higher $\mathrm{NO}_{\mathrm{x}}: \mathrm{HNO}_{3}$ observations and higher cut-points cause $\tau_{\mathrm{UNH}}$ to be shorter than the standard $\overline{\tau_{\text {air }}}$. Using the higher CIT measurements increases $\mathrm{NO}_{\mathrm{x}}: \mathrm{HNO}_{3}$ values and shifts the $\mathrm{NO}_{\mathrm{x}}: \mathrm{HNO}_{3}$ age bin cut-points to lower values. With lower cut-points, we might expect an increased $\tau_{\text {CIT }}$ relative to the adjusted values. The 


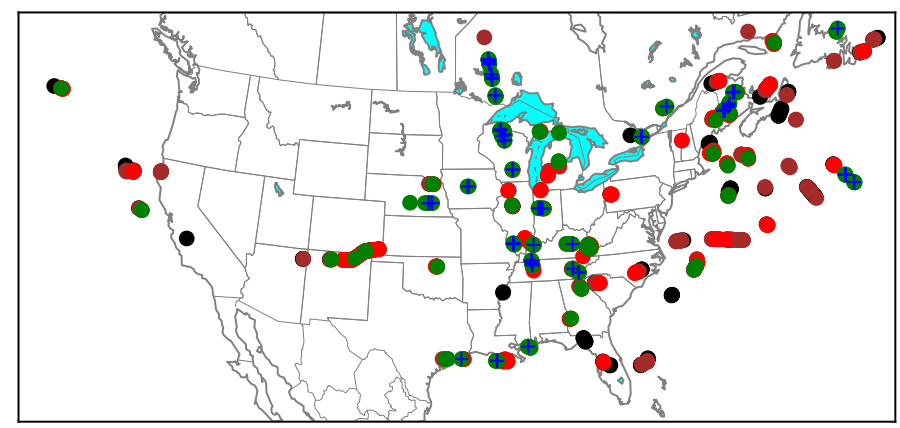

+ initial $\bullet$ fresh $\bullet$ young $\bullet$ mid-age $\bullet$ old

Latitude for aging air parcels Observations

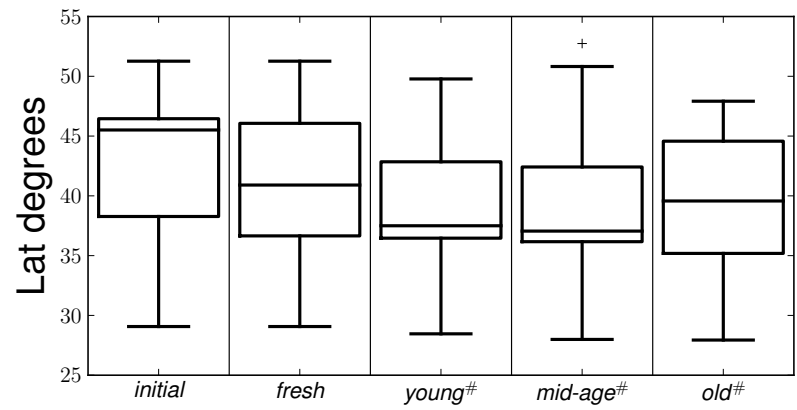

Longitude for aging air parcels Observations

Fig. A1. Map (a) and distribution (b, c) of spatial locations of aircraft observations categorized by age groups (initial, fresh, young, mid-age,

and old). Age group definitions are shown in Fig. 4.

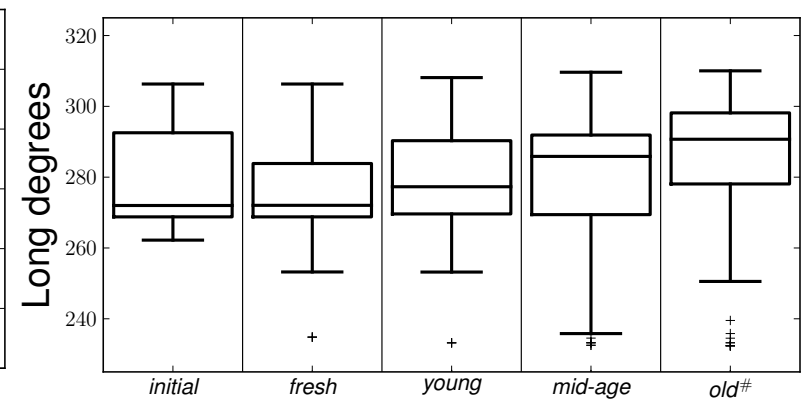
NOAA HYSPLIT MODEL

Backward trajectories ending at 1700 UTC 17 Jul 04 CDC1 Meteorological Data

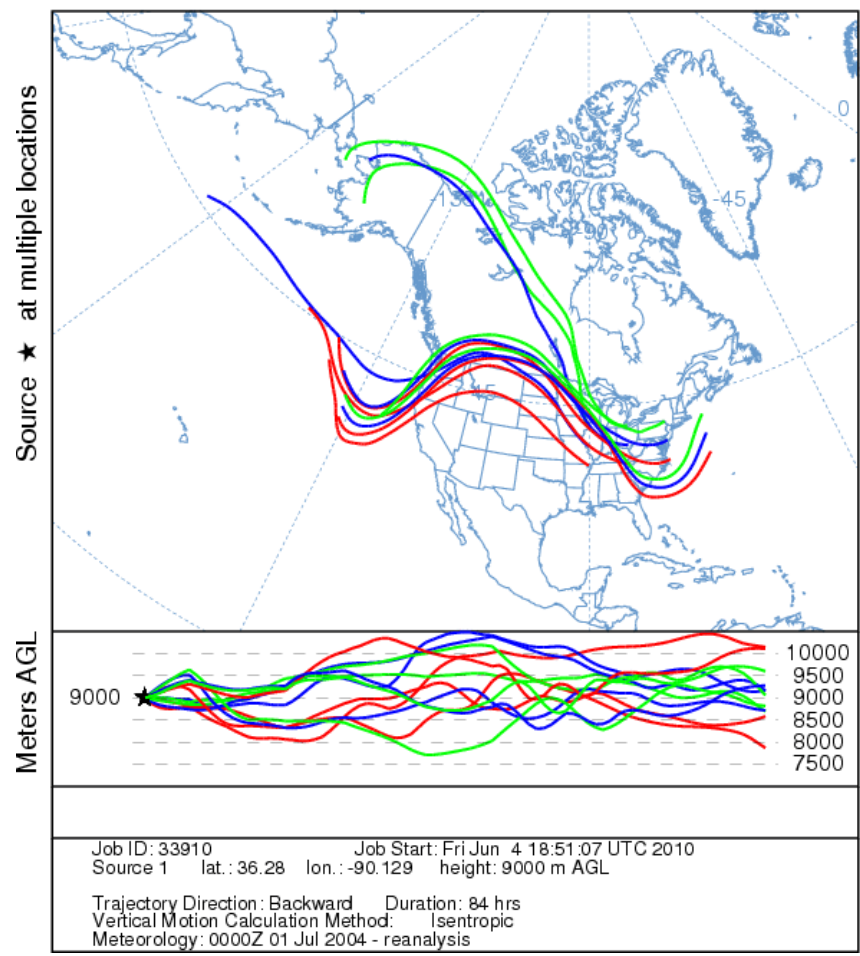

Fig. A2. HYSPLIT back trajectories for 12 northeast locations at $9 \mathrm{~km}$ altitude with only more than half of the air parcels originating between 8 and $10 \mathrm{~km}$. 

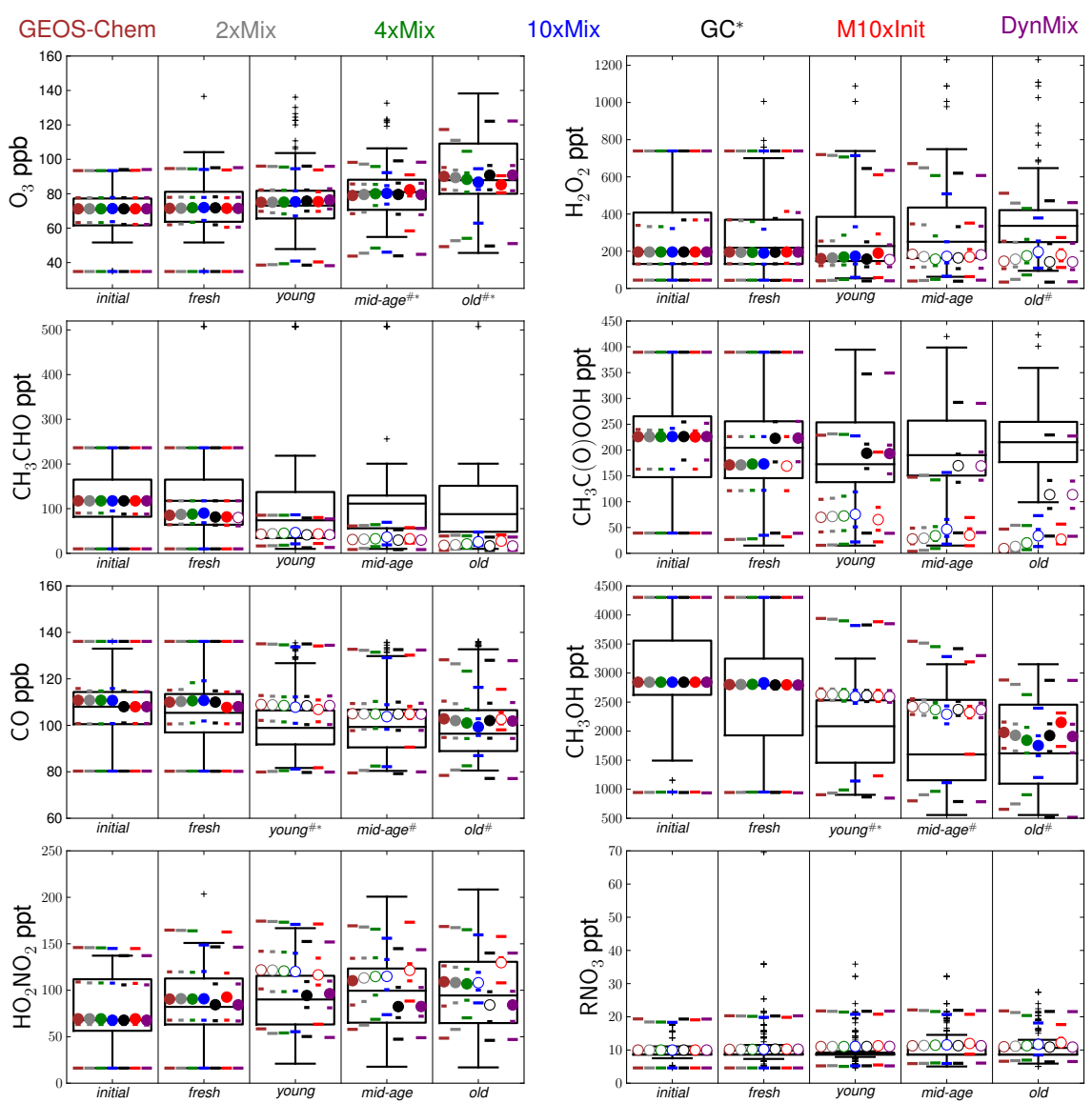

Fig. A3. Same as Fig. 5, but for GEOS-Chem with standard and alternate background mixing.
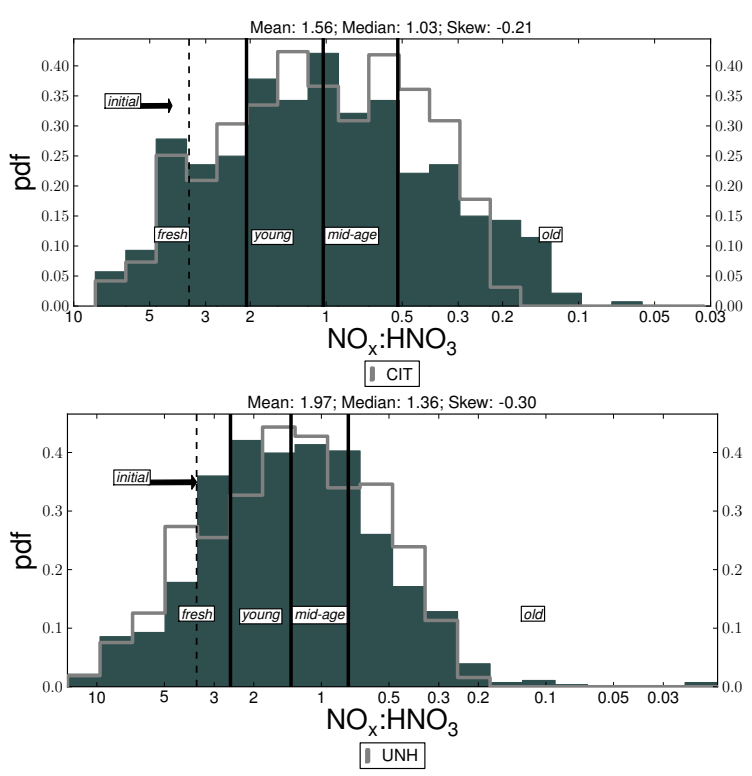

Fig. A4. Observed $\mathrm{NO}_{\mathrm{x}}: \mathrm{HNO}_{3}$ (bars; left: CIT, right: UNH) compared to simulated (lines) from the GEOS-Chem chemical mechanism using the optimized, bias-corrected statistical model.

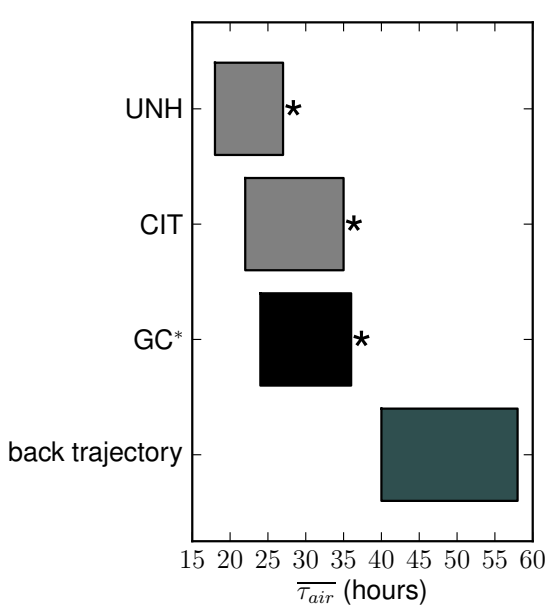

Fig. A5. Estimated mean air parcel lifetimes $\left(\overline{\tau_{\text {air }}}\right)$ derived from back trajectory and chemical simulation. Chemical simulations use our updated GEOS-Chem mechanism with the adjusted $\mathrm{HNO}_{3}$, the unadjusted CIT measurement, or the UNH unadjusted measurement. Asterisks indicate whether chemically simulated $\mathrm{NO}_{\mathrm{X}}: \mathrm{HNO}_{3}$ is statistically consistent with observations $(\alpha<0.01)$ when using the exponential (left, Eq. 3) and bias-corrected (right, Eq. 4) statistical models. 
CIT measurements, however, extend the distributions lowvalue tail that the model cannot capture without over predicting values from 0.2 to 0.5 . Because our goodness-of-fit statistic is sensitive to the whole distribution, $\tau_{\mathrm{CIT}}$ is 1 hour shorter than when using adjusted $\mathrm{HNO}_{3}$ values.

Using either measurement by itself increases the discrepancy between $\overline{\tau_{\text {air }}}$ inferred from back trajectories and $\overline{\tau_{\text {air }}}$ inferred from chemical simulation. By increasing the discrepancy, using either measurement by itself increases our estimation of the chemistry-based $\mathrm{NO}_{2}$ low-bias.

Acknowledgements. Special thanks for DC8 observational data to Melody Avery, Donald Blake, William Brune, Alan Fried, Brian Heikes, Greg Huey, Glen Sachse, Hanwant Singh, and the INTEX team. Thank you to Paul Wennberg for helpful conversation about the upper troposphere. Thank you to Gao Chen for helping identify and document the INTEX $\mathrm{HO}_{\mathrm{x}}$ corrections. Thank you to Mat Evans for help with the Dynamically Simple Model of Atmospheric Chemical Complexity.

This research was supported in part by an appointment to the Research Participation Program at the National Exposure Research Laboratory, US Environmental Protection Agency administered by the Oak Ridge Institute for Science and Education through an interagency agreement between the US Department of Energy and EPA.

In addition to the EPA program William R. Stockwell was supported in part by the NOAA Educational Partnership Program with Minority Serving Institutions (EPP/MSI) under grant number of NA06OAR4810172 through the NOAA Center for Atmospheric Sciences (NCAS) and National Science Foundation grant award number: 0653997.

Askar Fahr thanks NASA-Outer Planets Research Program for partial support of this work under Contract \#NNX08AQ68G at Howard University.

Disclaimer: Although this paper has been reviewed by the EPA and approved for publication, it does not necessarily reflect EPA's policies or views.

Edited by: N. Riemer

\section{References}

Atkinson, R., Baulch, D. L., Cox, R. A., Crowley, J. N., Hampson, R. F., Hynes, R. G., Jenkin, M. E., Rossi, M. J., and Troe, J.: Evaluated kinetic and photochemical data for atmospheric chemistry: Volume $\mathrm{I}$ - gas phase reactions of $\mathrm{O}_{\mathrm{x}}, \mathrm{HO}_{\mathrm{x}}, \mathrm{NO}_{\mathrm{x}}$ and $\mathrm{SO}_{\mathrm{x}}$ species, Atmos. Chem. Phys., 4, 1461-1738, doi:10.5194/acp-41461-2004, 2004.

Atkinson, R., Baulch, D. L., Cox, R. A., Crowley, J. N., Hampson, R. F., Hynes, R. G., Jenkin, M. E., Rossi, M. J., Troe, J., and IUPAC Subcommittee: Evaluated kinetic and photochemical data for atmospheric chemistry: Volume II - gas phase reactions of organic species, Atmos. Chem. Phys., 6, 3625-4055, doi:10.5194/acp-6-3625-2006, 2006.

Bertram, T. H., Perring, A. E., Wooldridge, P. J., Crounse, J. D., Kwan, A. J., Wennberg, P. O., Scheuer, E., Dibb, J., Avery, M. A., Sachse, G. W., Vay, S. A., Crawford, J. H., McNaughton, C. S., Clarke, A., Pickering, K. E., Fuelberg, H.,
Huey, G., Blake, D. R., Singh, H. B., Hall, S. R., Shetter, R. E., Fried, A., Heikes, B. G., and Cohen, R. C.: Direct measurements of the convective recycling of the upper troposphere, Science, 315, 816-820, doi:10.1126/science.1134548, 2007.

Carter, W. P.: Documentation of the SAPRC-99 Chemical Mechanism for VOC Reactivity Assessment, final report to California Air Resources Board, Contract 92-329 and 95-308, Calif. Air Res. Board, Sacramento, CA, USA, 2000.

Carter, W. P.: Development of the SAPRC-07 Chemical Mechanism and Updated Ozone Reactivity Scales, Final Report to the California Air Resources Board Contract No. 03-318, Calif. Air Res. Board, Sacramento, CA, USA, http://www.engr.ucr.edu/ carter/ SAPRC/saprc07.pdf, 2009.

Dodge, M.: Chemical oxidant mechanisms for air quality modeling: critical review, Atmos. Environ., 34, 2103-2130, 2000.

Draxler, R. and Hess, G.: Description of the HYSPLIT 4 modeling system, NOAA Technical Memorandum ERL ARL-224, p. 24, 1997.

Emmerson, K. M. and Evans, M. J.: Comparison of tropospheric gas-phase chemistry schemes for use within global models, Atmos. Chem. Phys., 9, 1831-1845, doi:10.5194/acp-9-1831-2009, 2009.

Emmons, L., Walters, S., Hess, P., Lamarque, J., Pfister, G., Fillmore, D., Granier, C., Guenther, A., Kinnison, D., Laepple, T., Orlando, J., Tie, X., Tyndall, G., Wiedinmyer, C., Baughcum, S., and Kloster, S.: Description and evaluation of the Model for Ozone and Related chemical Tracers, version 4 (MOZART-4), Geosci. Model Develop., 3, 43-67, 2010.

Evans, M. and Jacob, D.: Impact of new laboratory studies of $\mathrm{N}_{2} \mathrm{O}_{5}$ hydrolysis on global model budgets of tropospheric nitrogen oxides, ozone, and OH, Geophys. Res. Lett., 32, 1-4, 2005.

Eyers, C., Norman, P., Middel, J., Plohr, M., Michot, S., Atkinson, K., and Christou, R.: AERO2k Global Aviation Emissions Inventories for 2002 and 2025, 2004.

Fang, Y., Fiore, A., Horowitz, L., Levy II, H., Hu, Y., and Russell, A.: Sensitivity of the $\mathrm{NO}_{\mathrm{y}}$ budget over the United States to anthropogenic and lightning $\mathrm{NO}_{\mathrm{x}}$ in summer, J. Geophys. Res. 115, D18312, doi:10.1029/2010JD014079, 2010.

Fuelberg, H. E., Porter, M. J., Kiley, C. M., Halland, J. J., and Morse, D.: Meteorological conditions and anomalies during the Intercontinental Chemical Transport Experiment - North America, J. Geophys. Res., 112, 1-22, doi:10.1029/2006JD007734, 2007.

Gallager, R. G.: Discrete Stochastic Processes, Kluwer Academic Publishers, Boston Dordrecht London, 1996.

Gierczak, T., Jimenez, E., Riffault, V., and Burkholder, J.: Thermal decomposition of $\mathrm{HO}_{2} \mathrm{NO}_{2}$ (peroxynitric acid, PNA): Rate coefficient and Determination of the Enthalpy of Formation, J. Phys. Chem., 109, 586-596, http://pubs.acs.org/doi/abs/10.1021/ jp046632f, 2005.

Goliff, W. S. and Stockwell, W. R.: The Regional Atmospheric Chemistry Mechanism, Version 2 An Update, in: Atmospheric Chemical Mechanisms, University of California Davis, 2008.

Goliff, W., Stockwell, W., and Fahr, A.: The Regional Atmospheric Chemistry Mechanism, Version 2, in preparation, 2011.

Hudman, R., Jacob, D., Turquety, S., Leibensperger, E., Murray, L., Wu, S., Gilliland, A., Avery, M., Bertram, T., Brune, W., Cohen, R., Dibb, J., Flocke, F., Fried, A., Holloway, J., Neuman, J., Orville, R., Perring, A., Ren, X., Sachse, G., Singh, H., 
Swanson, A., and Wooldridge, P.: Surface and lightning source of nitrogen oxides over the United States: Magnitudes, chemical evolution, and outflow, J. Geophys. Res., 112, D12S05, doi:10.1029/2006JD007912, 2007.

Jaeglé, L., Jacob, D., Wang, Y., and Weinheimer, A.: Sources and chemistry of $\mathrm{NO}_{\mathrm{x}}$ in the upper troposphere over the United States, Geophys. Res. Lett., 25(10), 1709-1712, doi:10.1029/97GL03591, 1998.

Jimenez, E., Gierczak, T., Stark, H., and Burkholder, J.: Reaction of $\mathrm{OH}$ with $\mathrm{HO}_{2} \mathrm{NO}_{2}$ (Peroxynitric Acid): Rate coefficients between 218 and $335 \mathrm{~K}$ and product yields at $298 \mathrm{~K}, \mathrm{~J}$. Phys. Chem., 108, 1139-1149, http://pubs.acs.org/doi/abs/10. 1021/jp0363489, 2004.

Lacis, A., Wuebbles, D., and Logan, J.: Radiative forcing of climate by changes in the vertical distribution of ozone, J. Geophys. Res., 95, 9971-9982, 1990.

Madronich, S.: The Tropospheric Visible Ultra-violet (TUV) model web page., http://www.acd.ucar.edu/TUV/, 2002.

Mann, H. and Whitney, D.: On a test of whether one of two random variables is stochastically larger than the other, Ann. Math. Stat., 18, 50-60, 1947.

Mao, J., Carouge, C., Evans, M., Millet, D., and Palmer, P.: GEOS-Chem Chemical Mechanism Version 8-02-04, http://acmg.seas.harvard.edu/geos/wiki_docs/chemistry/ chemistry_updates_v6.pdf, 2009.

Murphy, J. G., Thornton, J. A., Wooldridge, P. J., Day, D. A., Rosen, R. S., Cantrell, C., Shetter, R. E., Lefer, B., and Cohen, R. C.: Measurements of the sum of $\mathrm{HO}_{2} \mathrm{NO}_{2}$ and $\mathrm{CH}_{3} \mathrm{O}_{2} \mathrm{NO}_{2}$ in the remote troposphere, Atmos. Chem. Phys., 4, 377-384, doi:10.5194/acp-4-377-2004, 2004.

Napelenok, S. L., Pinder, R. W., Gilliland, A. B., and Martin, R. V.: A method for evaluating spatially-resolved $\mathrm{NO}_{\mathrm{x}}$ emissions using Kalman filter inversion, direct sensitivities, and spacebased $\mathrm{NO}_{2}$ observations, Atmos. Chem. Phys., 8, 5603-5614, doi:10.5194/acp-8-5603-2008, 2008.

Olson, J., Crawford, J., Davis, D., Chen, G., Avery, M., Barrick, J., Sachse, G., Vay, S., Sandholm, S., and Tan, D.: Seasonal differences in the photochemistry of the South Pacific: a comparison of observations and model results from PEM-Tropics A and B, J. Geophys. Res., 106, 32749-32766, 2001.

Olson, J. R., Crawford, J., Chen, G., Brune, W. H., Faloona, I. C., Tan, D., Harder, H., and Martinez, M.: A reevaluation of airborne $\mathrm{HO}_{\mathrm{x}}$ observations from NASA field campaigns, J. Geophys. Res.-Atmos., 111, D10301, doi:10.1029/2005JD006617, 2006.

Orlando, J. and Tyndall, G.: Fall Meet. Suppl., Abstract A61B0078, Eos Trans. AGU, 83, 2002.

Pickering, K., Pinder, R., Prados, A., Allen, D., Stehr, J., Dickerson, R., Ehrman, S., Szykman, J., Celarier, E., and Gleason, J.: Use of OMI Data in Monitoring Air Quality Changes Resulting from $\mathrm{NO}_{\mathrm{x}}$ Emission Regulations over the United States, 2009 CMAS Conference, 1-19, 2009.

Prather, M. and Jacob, D.: A persistent imbalance in $\mathrm{HO}_{\mathrm{x}}$ and $\mathrm{NO}_{\mathrm{x}}$ photochemistry of the upper troposphere driven by deep tropical convection, Geophys. Res. Lett., 24, 3189-3192, 1997.
Real, E., Law, K. S., Schlager, H., Roiger, A., Huntrieser, H., Methven, J., Cain, M., Holloway, J., Neuman, J. A., Ryerson, T., Flocke, F., de Gouw, J., Atlas, E., Donnelly, S., and Parrish, D.: Lagrangian analysis of low altitude anthropogenic plume processing across the North Atlantic, Atmos. Chem. Phys., 8, 77377754, doi:10.5194/acp-8-7737-2008, 2008.

Ren, X., Olson, J. R., Crawford, J. H., Brune, W. H., Mao, J., Long, R. B., Chen, Z., Chen, G., Avery, M. A., Sachse, G. W., Barrick, J. D., Diskin, G. S., Huey, L. G., Fried, A., Cohen, R. C., Heikes, B. G., Wennberg, P. O., Singh, H. B., Blake, D. R., and Shetter, R. E.: $\mathrm{HO}_{\mathrm{x}}$ chemistry during INTEX-A 2004: observation, model calculation, and comparison with previous studies, J. Geophys. Res., 113, 1-13, doi:10.1029/2007JD009166, 2008.

Sander, S., Friedl, R. R., Golden, D. M., Kurylo, M. J., Moortgat, G. K., Wine, P. H., Ravishankara, A. R., Kolb, C. E., Molina, M. J., Finlayson-Pitts, B. J., Huie, R. E., and Orkin, V.: Chemical Kinetics and Photochemical Data for Use in Atmospheric Studies Evaluation Number 15, JPL Publ., 2006.

Saunders, S., Jenkin, M., and Derwent, R.: Report summary: web site of a Master Chemical Mechanism (MCM) for use in tropospheric chemistry models, Atmos. Environ., 31, 1249, doi:10.1016/S1352-2310(97)85197-7, 1997.

Sandu, A. and Sander, R.: KPP-2.1 User's Manual The Kinetic PreProcessor KPP An Environment for the Simulation of Chemical Kinetic Systems, 1-29, 2005.

Scholz, F. and Stephens, M.: K-sample Anderson-Darling tests, J. Am. Stat. Assoc., 82(399), 918-924, 1987.

Singh, H. B., Brune, W. H., Crawford, J., Jacob, D. J., and Russel, P.: Overview of the summer 2004 Intercontinental Chemical Transport Experiment - North America (INTEX-A), J. Geophys. Res, 111, D24S01, doi:10.1029/2006JD007905, 2006.

Singh, H. B., Salas, L., Herlth, D., Kolyer, R., Czech, E., Avery, M. A., Crawford, J., Pierce, R., Sachse, G. W., Blake, D. R., Cohen, R. C., Bertram, T. H., Perring, A. E., Wooldridge, P. J., Dibb, J., Huey, G., Hudman, R., Turquety, S., Emmons, L., Flocke, F., Tang, Y., Carmichael, G., and Horowitz, L.: Reactive nitrogen distribution and partitioning in the North American troposphere and lowermost stratosphere, J. Geophys. Res, 112, D12S04, doi:10.1029/2006JD007664, 2007.

Stockwell, W. R., Goliff, W. S., Pinder, R. W., Sarwar, G., Mathur, R., Schere, K. L., and Fahr, A.: A model comparison of nitrogen-containing compounds in the free troposphere using three mechanisms: RACM2, CB05 and SAPRC99, in: Eos Trans. AGU, vol. 89(53) of Fall Meet. Suppl., Abstract A54C08, 2008.

Sutkus, D., Baughcum, S., and DuBois, D.: Commercial aircraft emission scenario for 2020: Database Development and Analysis, National Aeronautics and Space Administration, Glenn Research Center, Washington, 2003.

Wennberg, P., Hanisco, T., Jaegle, L., Jacob, D., Hintsa, E., Lanzendorf, E., Anderson, J., Gao, R.-S., Keim, E., Donnelly, S., Negro, L. D., Fahey, D., McKeen, S., Salawitch, R., Webster, C., May, R., Herman, R., Proffitt, M., Margitan, J., Atlas, E., Schauffler, S., Flocke, F., McElroy, C., and Bui, T.: Hydrogen radicals, nitrogen radicals, and the production of $\mathrm{O}_{3}$ in the upper troposphere, Science, 279, 49-53, doi:10.1126/science.279.5347.49, 1998. 
Wild, O., Zhu, X., and Prather, M. J.: Fast-J: accurate simulation of in-and below-cloud photolysis in tropospheric chemical models, J. Atmos. Chem., 37, 245-282, http://www.springerlink. com/index/Q532038171841385.pdf, 2000.

Yarwood, G., Yocke, M., and Whitten, G. Z.: Updates to the Carbon Bond Chemical Mechanism: CB05, http://camx.com/publ/pdfs/ CB05_Final_Report_120805.pdf, 2005.
Yu, S., Mathur, R., Sarwar, G., Kang, D., Tong, D., Pouliot, G., and Pleim, J.: Eta-CMAQ air quality forecasts for $\mathrm{O}_{3}$ and related species using three different photochemical mechanisms (CB4, CB05, SAPRC-99): comparisons with measurements during the 2004 ICARTT study, Atmos. Chem. Phys., 10, 30013025, doi:10.5194/acp-10-3001-2010, 2010. 